\title{
Fuel Grading Study on a Low-Enriched Uranium Fuel Design for the High Flux Isotope Reactor
}

March 31, 2010

Prepared by

Germina llas

R. T. Primm, III

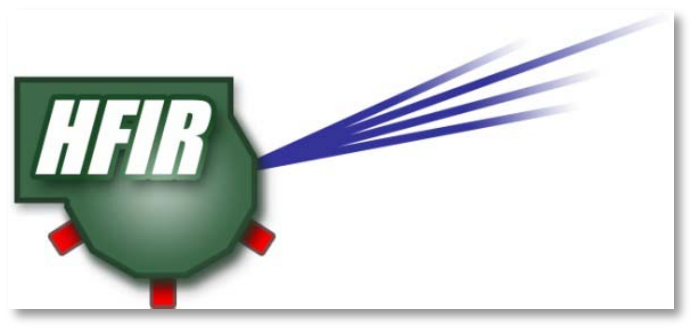




\section{DOCUMENT AVAILABILITY}

Reports produced after January 1, 1996, are generally available free via the U.S. Department of Energy (DOE) Information Bridge.

Web site http://www.osti.gov/bridge

Reports produced before January 1, 1996, may be purchased by members of the public from the following source.

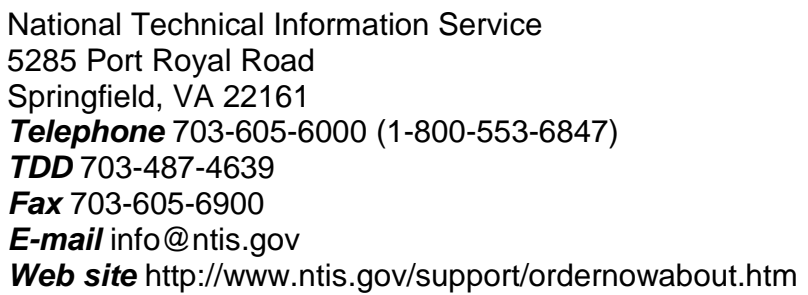

Reports are available to DOE employees, DOE contractors, Energy Technology Data Exchange (ETDE) representatives, and International Nuclear Information System (INIS) representatives from the following source.

Office of Scientific and Technical Information

P.O. Box 62

Oak Ridge, TN 37831

Telephone 865-576-8401

Fax 865-576-5728

E-mail reports@osti.gov

Web site http://www.osti.gov/contact.html

This report was prepared as an account of work sponsored by an agency of the United States Government. Neither the United States Government nor any agency thereof, nor any of their employees, makes any warranty, express or implied, or assumes any legal liability or responsibility for the accuracy, completeness, or usefulness of any information, apparatus, product, or process disclosed, or represents that its use would not infringe privately owned rights. Reference herein to any specific commercial product, process, or service by trade name, trademark, manufacturer, or otherwise, does not necessarily constitute or imply its endorsement, recommendation, or favoring by the United States Government or any agency thereof. The views and opinions of authors expressed herein do not necessarily state or reflect those of the United States Government or any agency thereof. 
Nuclear Science and Technology Division

\section{FUEL GRADING STUDY ON A LOW-ENRICHED URANIUM FUEL DESIGN FOR THE HIGH FLUX ISOTOPE REACTOR}

Germina Ilas

R. T. Primm, III

Date Published: March 2010

Prepared by

OAK RIDGE NATIONAL LABORATORY

Oak Ridge, Tennessee 37831-6283

managed by

UT-BATTELLE, LLC

for the

U.S. DEPARTMENT OF ENERGY

under contract DE-AC05-00OR22725 



\section{CONTENTS}

LIST OF FIGURES

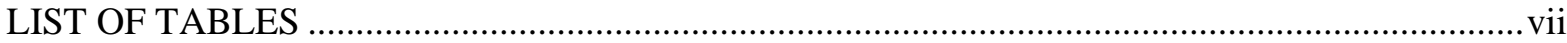

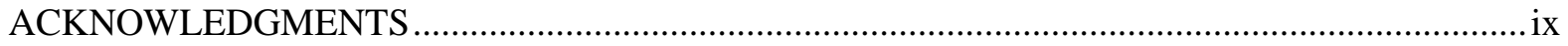

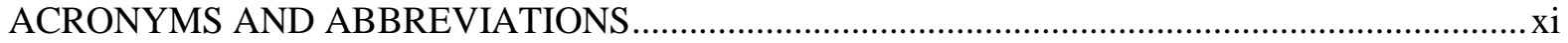

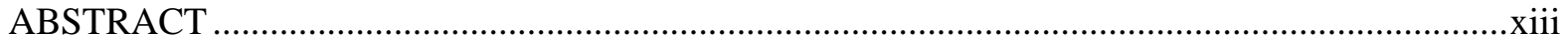

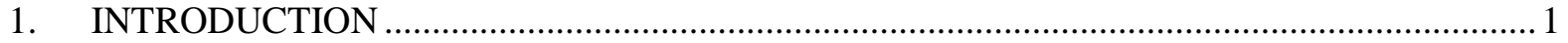

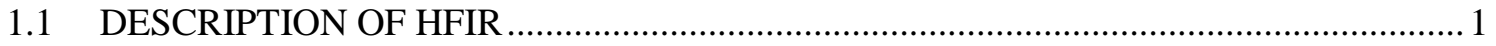

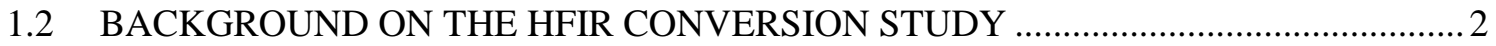

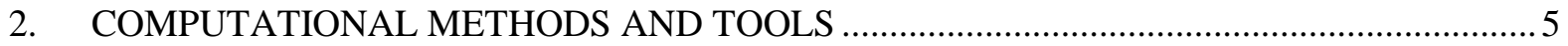

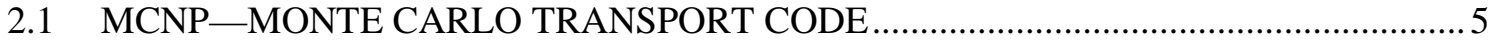

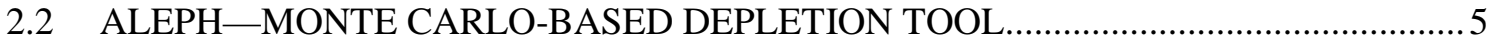

2.3 BOLD-VENTURE-DIFFUSION THEORY-BASED REACTOR ANALYSIS

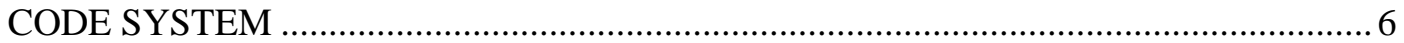

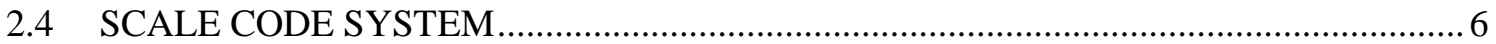

2.5 THERMAL HYDRAULIC ANALYSES-THE HFIR STEADY STATE HEAT

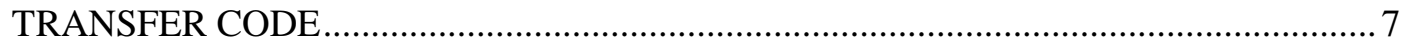

3. MONTE CARLO DEPLETION MODEL FOR HFIR LEU CONFIGURATIONS .................... 9

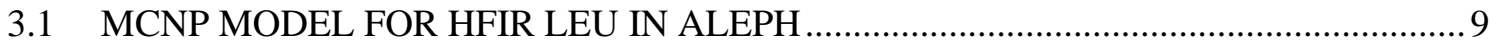

3.1.1 Optimization of the MCNP Model for HFIR LEU in ALEPH............................. 12

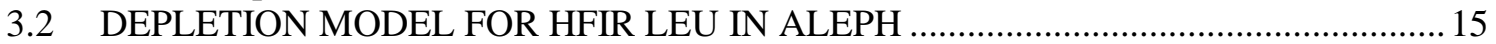

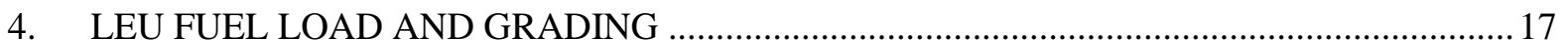

4.1 VARIATION OF $K_{\text {EFF }}$ AS A FUNCTION OF THE LEU FUEL LOAD.......................... 17

4.2 SEARCH FOR AN OPTIMAL LEU FUEL GRADING ................................................. 19

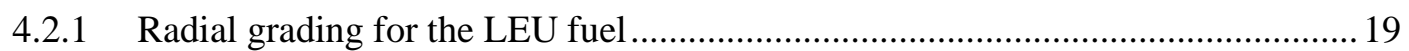

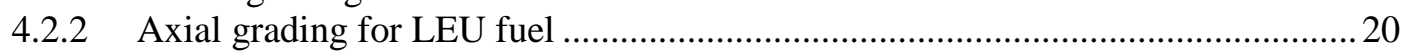

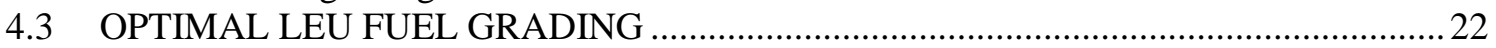

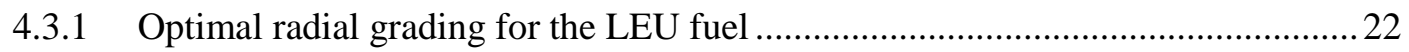

4.3.2 Optimal axial grading for the LEU fuel ...........................................................22

5. PERFORMANCE AND SAFETY PARAMETERS FOR THE HFIR LEU CORE ..................25

5.1 PERFORMANCE PARAMETERS FOR THE HFIR LEU CORE .....................................25

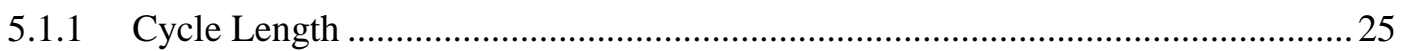

5.1.2 Core Power Distribution................................................................................... 25

5.1.3 Peak Physics Parameters Relevant to Irradiation Tests....................................... 25

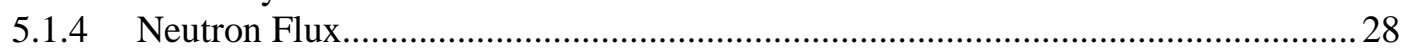

5.2 SAFETY AND SAFEGUARDS PARAMETERS FOR THE HFIR LEU CORE .............29

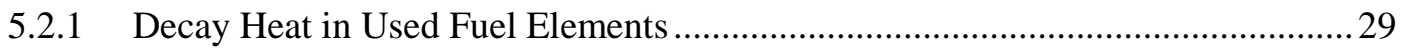

5.2.2 Isotopic Compositions in Used Fuel Elements................................................. 31

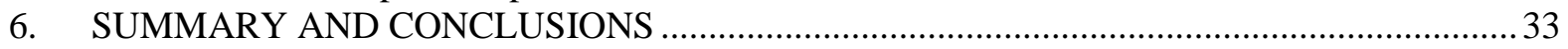

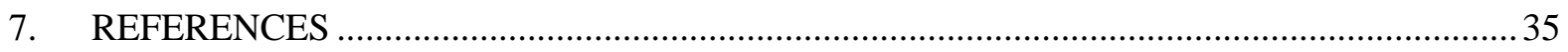

Appendix A. Material composition for LEU fuel............................................................................ 



\section{FIGURES}

Page

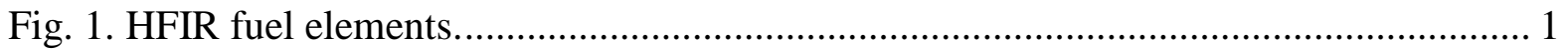

Fig. 2. "Flat plate" profiles of fuel meat regions for HEU fuel. ........................................... 3

Fig. 3. Cross section of the MCNP model for HFIR LEU at core axial midline................... 10

Fig. 4. Axial cross section of the MCNP model for HFIR LEU........................................ 10

Fig. 5. Flux trap region in the LEU core model (radial view) ........................................... 11

Fig. 6. A 3-D MCNP simplified model for HFIR LEU................................................... 13

Fig. 7. Axial variation of neutron thermal flux in fuel elements. ...................................... 14

Fig. 8. Radial variation of neutron thermal flux in fuel elements. ........................................ 14

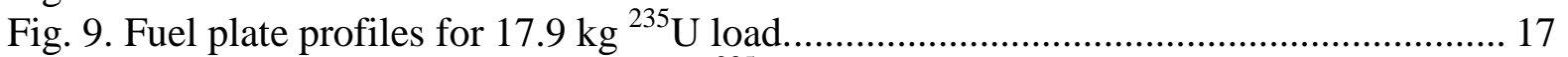

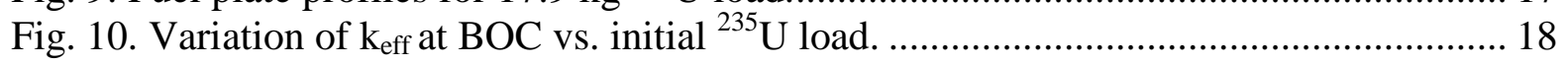

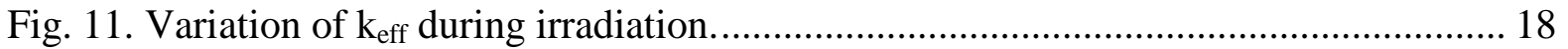

Fig. 12. Iterative search for an optimal LEU fuel design................................................ 19

Fig. 13. Final radial grading profile for LEU fuel plates............................................... 20

Fig. 14. Initial axial grading profiles for LEU fuel..................................................... 21

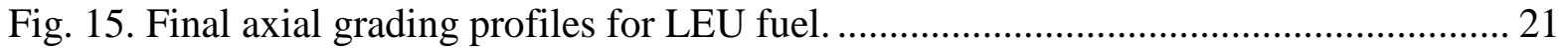

Fig. 16. Optimal radial grading profile for LEU fuel plates............................................. 23

Fig. 17. Axial grading profiles for LEU fuel (0-3 cm from bottom of fuel element)........... 24

Fig. 18. Decay heat for used fuel-comparison of HEU cycle 400 and LEU cores. ............. 29 



\section{TABLES}

Page

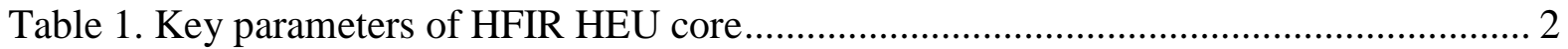

Table 2. Composition of curium targets in the HFIR LEU core model................................ 9

Table 3. Radial fuel regions in the MCNP model for HFIR LEU ...................................... 11

Table 4. Axial fuel regions in the MCNP model for HFIR LEU......................................... 12

Table 5. Radial fuel regions in the MCNP model for HFIR LEU ....................................... 22

Table 6. Relative fission density for HFIR LEU at BOC .................................................. 26

Table 7. Relative fission density for HFIR LEU at EOC ............................................... 27

Table 8. Peak performance parameters for LEU fuel in HFIR .......................................... 27

Table 9. Neutron flux at BOC—comparison of HEU cycle 400 and LEU cores .................. 28

Table 10. Neutron flux at EOC-comparison of HEU cycle 400 and LEU cores ................ 28

Table 11. Decay heat for used fuel — comparison of HEU ................................................. 29

Table 12. Major contributors to total decay heat at discharge-comparison ........................ 30

Table 13. Major actinides inventory for HEU ............................................................ 31

Table A.1 Material composition for LEU fuel............................................................. A-1 



\section{ACKNOWLEDGMENTS}

The authors would like to acknowledge that the support for this project was provided by the Global Threat Reduction Initiative, Reduced Enrichment for Research and Test Reactors Program, Nuclear National Security Administration, U.S. Department of Energy. Review of the manuscript by Steve Bowman, Nuclear Science and Technology Division, and Kevin A. Smith, Research Reactors Division, Oak Ridge National Laboratory, and the careful formatting of the document by Angie Alford are very much appreciated and acknowledged. A request for physics parameters from Daniel Wachs, Idaho National Laboratory let to the discovery of an error in Table 6 of the original version of this report (dated November 23, 2009). This version of the report includes a correction to Table 6 and a new table containing the peak physics parameters requested by Wachs (Table 8). 



\section{ACRONYMS AND ABBREVIATIONS}

$\begin{array}{ll}\text { 1-D } & \text { one-dimensional } \\ \text { 2-D } & \text { two-dimensional } \\ \text { 3-D } & \text { three-dimensional } \\ \text { BOC } & \text { beginning of cycle } \\ \text { C/E } & \text { calculated-to-experimental } \\ \text { CR } & \text { control element region } \\ \text { DOE } & \text { U.S. Department of Energy } \\ \text { EOC } & \text { end of cycle } \\ \text { FTT } & \text { flux trap target region } \\ \text { HEU } & \text { high-enriched uranium } \\ \text { HFIR } & \text { High Flux Isotope Reactor } \\ \text { IFE } & \text { inner fuel element } \\ \text { keff } & \text { effective multiplication constant } \\ \text { LEU } & \text { low-enriched uranium } \\ \text { LANL } & \text { Los Alamos Nuclear Laboratory } \\ \text { MIT } & \text { Massachusetts Institute of Technology } \\ \text { OFE } & \text { outer fuel element } \\ \text { ORNL } & \text { Oak Ridge National Laboratory } \\ \text { PB } & \text { permanent beryllium reflector region } \\ \text { RB } & \text { removable beryllium reflector region } \\ \text { RERTR } & \text { Reduced Enrichment for Research and Test Reactors Program } \\ \text { SCALE } & \text { Standardized Computer Analyses for Licensing Evaluations } \\ \text { SCK-CEN } & \text { Studiecentrum voor Kernenergie-Centre d'Étude de l'Energie Nucléaire }\end{array}$ 



\begin{abstract}
An engineering design study that would enable the conversion of the High Flux Isotope Reactor (HFIR) from high-enriched uranium to low-enriched uranium fuel is ongoing at Oak Ridge National Laboratory. The computational models used to search for a low-enriched uranium (LEU) fuel design that would meet the requirements for the conversion study, and the recent results obtained with these models during FY 2009, are documented and discussed in this report. Estimates of relevant reactor performance parameters for the LEU fuel core are presented and compared with the corresponding data for the currently operating high-enriched uranium fuel core. These studies indicate that the LEU fuel design would maintain the current performance of the HFIR with respect to the neutron flux to the central target region, reflector, and beam tube locations.
\end{abstract}





\section{INTRODUCTION}

An engineering design study for a fuel that would enable the conversion of the High Flux Isotope Reactor (HFIR) from high-enriched uranium (HEU) to low-enriched uranium (LEU) is ongoing as part of an effort sponsored by the U.S. Department of Energy's (DOE) National Nuclear Security Administration through the Global Threat Reduction Initiative/Reduced Enrichment for Research and Test Reactors Program (RERTR). Given the unique fuel, particular core design, and high power density of HFIR, and the requirement that the impact of the fuel change on the core performance and operation be minimal, this conversion study represents a complex and challenging task. Such a task requires improvements in and extensions of the computational methodologies and tools that are currently used to support the operation of the reactor.

\subsection{DESCRIPTION OF HFIR}

The HFIR is an 85 MW, very high flux, pressurized light-water-cooled and moderated, flux-trap type reactor, which is operated at the Oak Ridge National Laboratory (ORNL). The primary mission of HFIR is to support neutron scattering experiments. Other missions include isotope production and materials irradiation research. The reactor core consists of a series of concentric annular regions: a central flux trap containing vertical experimental targets surrounded by two fuel elements separated by a thin water region, a region containing two control plates, a beryllium reflector, and a water region to the edge of the pressure vessel, which is located in a pool of water. Details of the reactor configuration and operation can be found elsewhere. ${ }^{1,2}$ For convenience, the core data of most relevance to the study discussed in this report are presented in Table 1.

The two fuel elements in HFIR are identified as inner fuel element (IFE) and outer fuel element (OFE). They are composed of numerous, involute-shaped fuel plates $1.27 \mathrm{~mm}$ thick, as illustrated in Fig. 1.(a). The plates are separated by a water-filled cooling channel $1.27 \mathrm{~mm}$ thick, and are held together by two cylindrical aluminum side walls. The fuel plates have a sandwich-type design with a fuel region enclosed in an aluminium-based clad, as illustrated in Fig. 1.(b). The fuel meat inside the fuel region contains a mixture of aluminium powder and uranium oxide $\left(\mathrm{U}_{3} \mathrm{O}_{8}\right)$ with $93.1 \mathrm{wt} \%{ }^{235} \mathrm{U}$ enrichment and is characterized by variable thickness along the width of the fuel plate (radial grading) and a uniform thickness along the length of the fuel plate for a given radius (no axial grading).

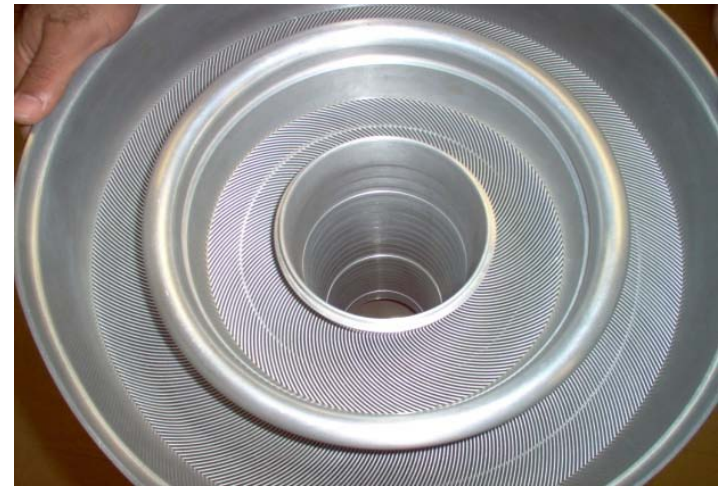

a) inner and outer fuel elements

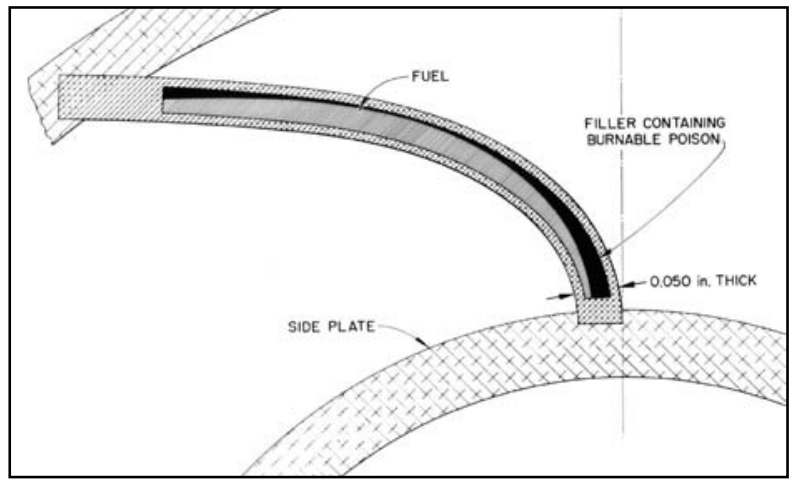

(b) fuel plate profile

Fig. 1. HFIR fuel elements. 
Table 1. Key parameters of HFIR HEU core

\begin{tabular}{|c|c|c|}
\hline Reactor data & & \\
\hline Operating power (MW) & & \\
\hline Cycle length (days) & & \\
\hline Number of fuel elements & & \\
\hline Fuel data & & \\
\hline Туре & & \\
\hline Enrichment (wt \% ${ }^{235} \mathrm{U}$ ) & & \\
\hline Total load ${ }^{235} \mathrm{U}(\mathrm{kg})$ & & \\
\hline Total load uranium (kg) & & \\
\hline Fuel elements data & Inner fuel element & Outer fuel element \\
\hline Load of ${ }^{235} \mathrm{U}(\mathrm{kg})$ & 2.6 & 6.8 \\
\hline Number of fuel plates & 171 & 369 \\
\hline Fuel plate width (cm) & 8.1 & 7.3 \\
\hline Fuel plate thickness $(\mathrm{cm})$ & 0.127 & 0.127 \\
\hline Coolant channel between plates $(\mathrm{cm})$ & 0.127 & 0.127 \\
\hline Fuel plate clad thickness $(\mathrm{cm})$ & 0.0254 & 0.0254 \\
\hline
\end{tabular}

\subsection{BACKGROUND ON THE HFIR CONVERSION STUDY}

In accordance with the U.S. nonproliferation policy to minimize and possibly eliminate the use of HEU fuel in civilian nuclear programs, the DOE RERTR Program has initiated and supported fuel development and engineering studies that would facilitate the conversion of high-performance U.S. research reactors from HEU fuel to LEU fuel. A study to assess the feasibility of converting HFIR to an LEU fuel and determine the performance goals for the candidate LEU fuel forms considered was initiated in 2006. Two types of high-density LEU fuels were initially under consideration and were studied: a fuel consisting of uranium-molybdenum (U-Mo) dispersion in aluminum and a monolithic U-Mo alloy fuel. The LEU fuel currently under consideration is a high-density monolithic alloy, U-10Mo, which contains $90 \mathrm{wt} \%$ uranium and $10 \mathrm{wt} \%$ natural molybdenum. It has a density of $17.02 \mathrm{~g} / \mathrm{cm}^{3}$ and an enrichment of 19.75 wt $\%{ }^{235} \mathrm{U}$.

As included in the key top-level assumptions established to guide the HFIR conversion study, ${ }^{3}$ there shall be no change in the physical dimensions of the core or fuel geometry, no reduction in the core power or core lifetime, and no major changes to the current control and protection systems, and the margins of safety in the bases of the currently approved Technical Safety Requirements ${ }^{4}$ shall be maintained.

The fuel meat is the region that will need to be changed when the current HEU fuel is replaced with LEU fuel, with no changes to the basic geometry of the fuel plate. In the current HEU fuel plate, the thickness of the fuel meat region varies smoothly along the width of the fuel plate; the corresponding flat plate (i.e., plate prior to rolling into an involute shape) profiles of the fuel regions are illustrated in Fig. 2 for the IFE and OFE, respectively. 

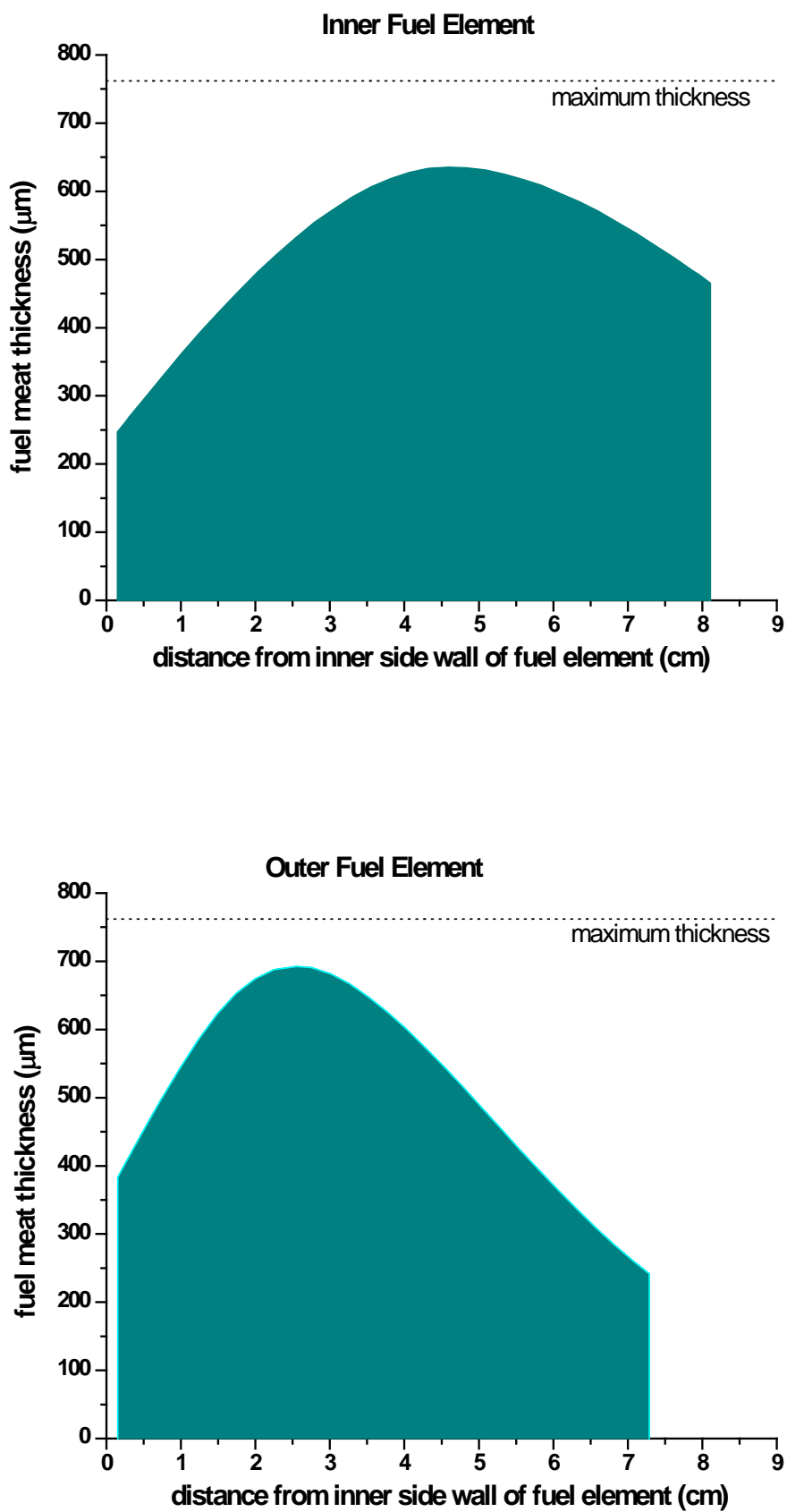

Fig. 2. "Flat plate" profiles of fuel meat regions for HEU fuel. 


\section{COMPUTATIONAL METHODS AND TOOLS}

The HFIR core analysis for an LEU fuel initially used as a basis for neutronics studies the standard set of computational methods and tools that are currently employed to support the operation of the HFIR HEU core. This set of tools include the Monte Carlo neutron transport code MCNP, ${ }^{5}$ the diffusion theorybased code system with depletion capabilities BOLD VENTURE, ${ }^{6}$ and the nuclear analysis code system SCALE. ${ }^{7}$ Taking advantage of the recent developments in computational methodologies and codes, the neutronics analyses for an LEU fuel have later evolved from diffusion-based depletion to Monte Carlobased depletion methodologies. A Monte Carlo-based depletion model for HFIR with LEU fuel, using the $\mathrm{ALEPH}^{8}$ computational tool, has been established and validated based on the core configuration and cycle length for a recent HFIR HEU fuel cycle. In addition, in order to improve the performance of the BOLD VENTURE deterministic LEU core model, a new cross section processing methodology has been developed to provide a better representation of the spatial dependence of the neutron flux, especially important for the fuel regions at the top and bottom of each fuel element. A brief description of the codes used for the LEU core analysis is provided in this section. The computational models will be presented in further sections of this report.

\subsection{MCNP-MONTE CARLO TRANSPORT CODE}

MCNP is a general-purpose Monte Carlo code developed at Los Alamos Nuclear Laboratory (LANL) that can be used to simulate the neutron, photon, electron, or coupled neutron/photon/electron transport, including the capability to calculate eigenvalues for critical systems, in three-dimensional (3-D) arbitrary geometry configurations. Its capabilities to model complex geometries and to use pointwise cross-section data for the neutron transport treatment make the code a desirable tool for analysis of highly heterogeneous systems such as HFIR. An MCNP model of the HFIR HEU reactor, which includes a detailed representation of the reactor components, was previously developed ${ }^{9}$ and has served as a reference model to perform analyses in support of HFIR operation. Based on the existing model for the HEU core, an MCNP model for the LEU fuel core has been developed and used in the design of a new LEU fuel for HFIR.

\subsection{ALEPH-MONTE CARLO-BASED DEPLETION TOOL}

ALEPH is a Monte Carlo-based depletion tool developed at SCK-CEN in Belgium. ALEPH couples a Monte Carlo transport code from the MCNP family of LANL codes (e.g., MCNP, MCNPX) and the point depletion and decay code ORIGEN 2.2. ${ }^{10}$ It is a relatively user-friendly code; if an appropriate MCNP model of the configuration to be analyzed is available, the changes and/or additions to this model are minimal. At each depletion step, the transport flux solution from MCNP is used to generate the cross section data for the ORIGEN 2.2 depletion calculation; the isotopic composition data resulting from ORIGEN 2.2 are used in the subsequent MCNP transport calculation to obtain cross sections for the next depletion step, and so forth in an iterative manner. Compared with other Monte Carlo depletion tools, ALEPH has a particular approach in determining from MCNP the data needed for the ORIGEN 2.2 depletion calculation. Whereas other tools obtain the cross sections for depletion based on reaction rate tallies in the Monte Carlo transport calculation, ALEPH requires only flux tallies in a fine-group structure. The one-group cross sections for ORIGEN 2.2 are obtained by weighting pre-generated pointwise cross section data with the MCNP-calculated fine-group flux. These pointwise cross section data are consistent with the cross section data used in the MCNP transport calculation, as both sets are precomputed based on the same ENDF/B data files. The user must obtain sufficient convergence in flux spectra to accurately collapse cross section data, but of course, the same is true for accurately determining 
cross sections for depletion with other Monte Carlo-based depletion codes. By calculating only the flux with MCNP, compared with calculating reaction rates in other codes, execution times for ALEPH are considerably less than for other Monte Carlo depletion tools.

As for any other Monte Carlo-based tool, the drawback of using ALEPH is the computational efficiency, especially when depletion calculations are involved. However, the capability of modeling the geometry in detail, including the explicit simulation of the control element movement during the cycle, and of using continuous energy cross section data for the neutron transport, make this tool an excellent choice for HFIR LEU depletion studies. In addition, improvement in computational efficiency can be achieved through the use of the software on a multi-processor platform (computer cluster).

\subsection{BOLD-VENTURE-DIFFUSION THEORY-BASED REACTOR ANALYSIS CODE SYSTEM}

The BOLD VENTURE code system treats the neutron transport using a multigroup diffusion theory approach in 3-D geometry, including the cylindrical geometry that is appropriate for the HFIR core analysis. This code system, which also has depletion capabilities, has been one of the tools used over the years, in conjunction with the MCNP code, for neutronics analyses of HFIR HEU performance. In particular, the code has served to obtain the power profile and the peak fluxes in the target and reflector regions of interest and to perform depletion simulations. Though it is not as accurate as a Monte Carlo transport code because of inherent limitations in the diffusion approximation for treatment of neutron transport, the ability to provide fast solutions, perform depletion calculations, and allow changes in the geometry during depletion (i.e., changes in the control element locations) makes BOLD VENTURE a suitable tool to perform fast scoping studies for LEU core configurations. Completion, in a short time frame, of numerous iterative design calculations required in the optimization of any new reactor fuel design would benefit from a deterministic solution method to help narrow the search space to a domain that can be further explored with more accurate methodologies.

\subsection{SCALE CODE SYSTEM}

SCALE (Standardized Computer Analyses for Licensing Evaluation) is a modular code system that has been developed and maintained by ORNL under support from the U.S. Nuclear Regulatory Commission and DOE. This code system uses automated sequences to provide cross-section processing, reactor lattice physics, criticality safety, radiation shielding, and spent fuel characterization analysis capabilities. SCALE has been used in HFIR analyses to generate few-group cross section libraries for use with BOLD VENTURE; perform source terms, decay heat, and dose calculations; or conduct criticality safety analyses.

The cross section processing methodology used previously for HFIR analyses is based on a set of modules in SCALE that perform resonance processing and one-dimensional (1-D) transport calculations based on a radial representation of the core. The use of these cross sections with a BOLD VENTURE model for HFIR LEU configurations resulted in relatively large differences in power density near the top and bottom of the fuel elements compared with the data calculated with an MCNP model. These regions of the HFIR core can be particularly challenging because of the significant changes in flux spectra near the radial reflector and the light-water coolant above and below the fuel elements. Recently, a new, improved cross section processing methodology for LEU fuel configurations was developed ${ }^{11}$ with the aim of ensuring a more appropriate representation of the cross section data for the fuel regions located near the edges of the fuel element. This new methodology is based on the discrete ordinates transport code NEWT ${ }^{12}$ available in SCALE, which allows two-dimensional (2-D) arbitrary-mesh geometry for neutron transport calculations. 


\subsection{THERMAL HYDRAULIC ANALYSES-THE HFIR STEADY STATE HEAT TRANSFER CODE}

The margin to incipient boiling, and therefore the determination of the maximum allowable operating power for the HFIR, is determined from custom-designed software that is described in Ref. 3 . The program requires, as input, reactor geometry, a 2-D (radial and axial) power profile as a function of irradiation time, and manufacturing uncertainty factors. Geometry and power profiles are known, but manufacturing uncertainty factors have not yet been defined for U-10Mo fuel. Since almost no data are available, the uncertainty values associated with the current HEU fuel and documented in Ref. 3 were used in the analyses reported here.

One set of measured data from which one uncertainty factor can be derived (variability in fuel thickness from design basis) was made available to the authors from staff at the Y-12 National Security Complex. Thickness measurements were made for $28 \mathrm{U} / \mathrm{Mo}$ foil plates at five locations along the length of each plate. All plates were to have been the same thickness, and the thickness was to have been constant along the plate. The average thickness for the 140 measurements was 16.5193 mils (412.98 microns). The standard deviation of the set of data was 1.992 mils (50.60 microns). The relative standard deviation was $12.06 \%$. Current HFIR fabrication criteria allow for a maximum deviation from design of $12 \%$. Consequently, by current criteria, approximately $17 \%$ of measurements would have failed the acceptance criterion. 


\section{MONTE CARLO DEPLETION MODEL FOR HFIR LEU CONFIGURATIONS}

\subsection{MCNP MODEL FOR HFIR LEU IN ALEPH}

The MCNP model used for the HFIR LEU configuration is based on the 3-D MCNP revised model for HFIR HEU cycle 400. ${ }^{9}$ The model is illustrated in Figs. 3 and 4, which show a radial cross section at the core midline and an axial cross section through the center of the core, respectively; various regions and materials are shown in different colors. The model, which explicitly represents the experiment locations in the central target region and beryllium reflector, includes six regions:

1. Flux trap target region (FTT)

2. Inner fuel element region (IFE)

3. Outer fuel element region (OFE)

4. Control element region (CR)

5. Removable beryllium reflector region (RB)

6. Permanent beryllium reflector region (PB)

As compared with the FTT model for revised cycle 400-in which 31 out of the 37 experimental locations in FTT included 28 dummy aluminum targets, one hydraulic tube, and two stainless steel targets - the LEU model contains one hydraulic tube and 30 curium targets in the interior basket, as illustrated in Fig. 5. The composition of the curium targets is listed in Table 2. The material composition data used for the LEU fuel plates are presented in Appendix A.

As used in the MCNP model for cycle 400, the LEU fuel in the IFE region is modeled by homogenizing the fuel meat and aluminum cladding of the fuel plates and the water in between the fuel plates. To approximate the variation of the ${ }^{235} \mathrm{U}$ content in the radial direction of the fuel plate (i.e., radial fuel grading), eight radial regions with different ${ }^{235} \mathrm{U}$ concentrations are used in the IFE modeling. A similar model is used for the OFE but with nine radial regions. The dimensions of the radial fuel regions in the IFE and OFE models are shown in Table 3. The concentration of ${ }^{235} \mathrm{U}$ in the axial direction was initially considered uniform, though axial grading was used in some of the studied cases. The dimensions for the axial layers are shown in Table 4. The axial layer dimensions were selected by studying the variation of the microscopic thermal fission cross section of ${ }^{235} \mathrm{U}$ as a function of the axial location, as will be further discussed. All regions located outside the fuel elements regions were represented as in the model for cycle 400 .

Table 2. Composition of curium targets in the HFIR LEU core model

\begin{tabular}{|l|c|c|c|}
\hline Nuclide ID & Atoms/b-cm & Nuclide ID & Atoms/b-cm \\
\hline O-16 & $6.6358 E-03$ & Am-243 & $3.7252 \mathrm{E}-05$ \\
Al-27 & $4.1858 E-02$ & Cm-242 & $1.1234 \mathrm{E}-09$ \\
Pu-238 & $1.4608 E-08$ & Cm-243 & $3.7128 \mathrm{E}-07$ \\
Pu-239 & $1.9706 E-08$ & $\mathrm{Cm}-244$ & $6.1759 \mathrm{E}-04$ \\
Pu-240 & $3.7969 \mathrm{E}-05$ & $\mathrm{Cm}-245$ & $9.2061 \mathrm{E}-06$ \\
Pu-242 & $1.1256 \mathrm{E}-09$ & $\mathrm{Cm}-246$ & $1.3000 \mathrm{E}-03$ \\
$\mathrm{Pu}-242$ & $2.9825 \mathrm{E}-07$ & $\mathrm{Cm}-247$ & $3.7719 \mathrm{E}-05$ \\
$\mathrm{Am}-241$ & $1.5978 \mathrm{E}-04$ & $\mathrm{Cm}-248$ & $2.5183 \mathrm{E}-04$ \\
$\mathrm{Am}-242$ & $4.2253 \mathrm{E}-07$ & $\mathrm{Am}-243$ & $3.7252 \mathrm{E}-05$ \\
\hline
\end{tabular}




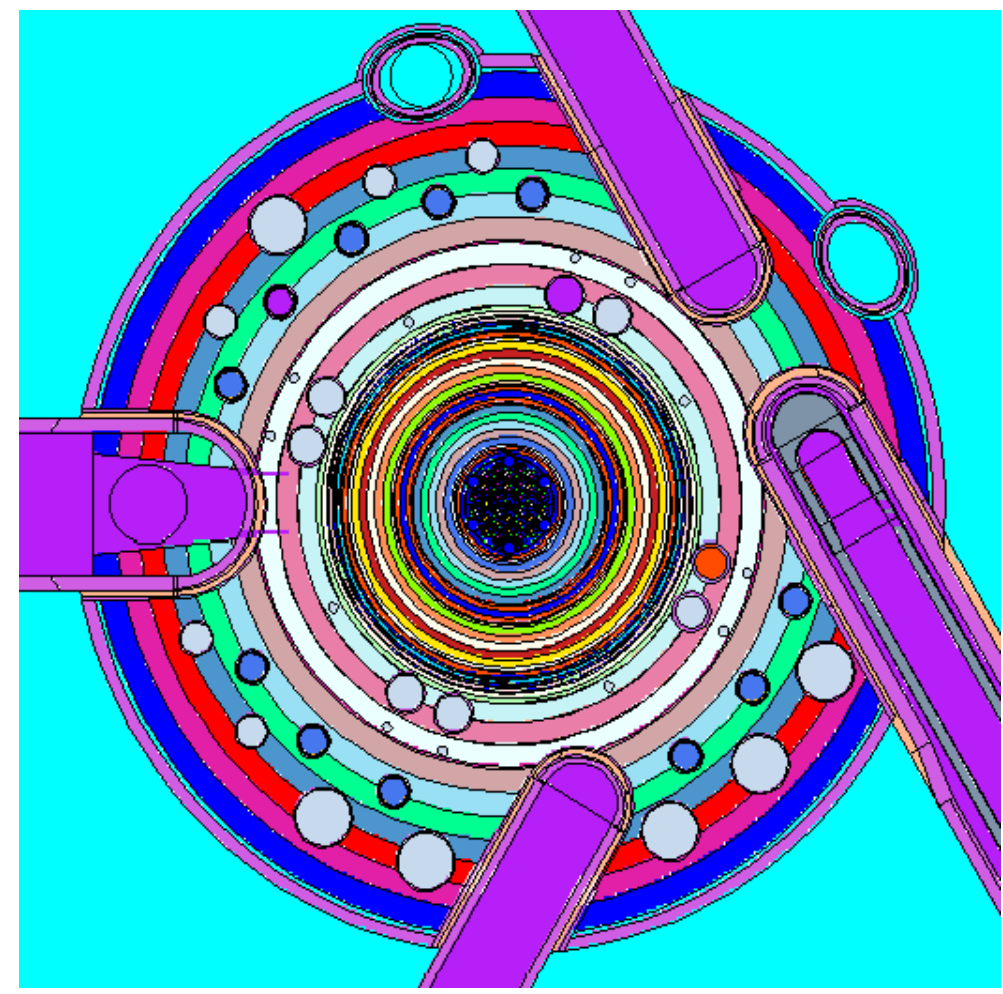

Fig. 3. Cross section of the MCNP model for HFIR LEU at core axial midline.

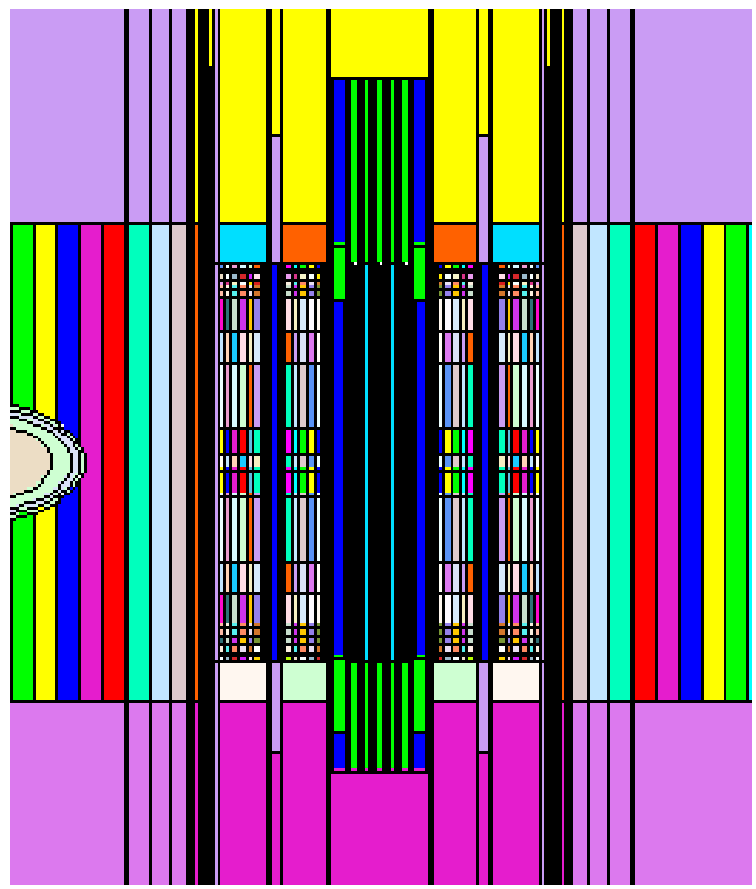

Fig. 4. Axial cross section of the MCNP model for HFIR LEU. 


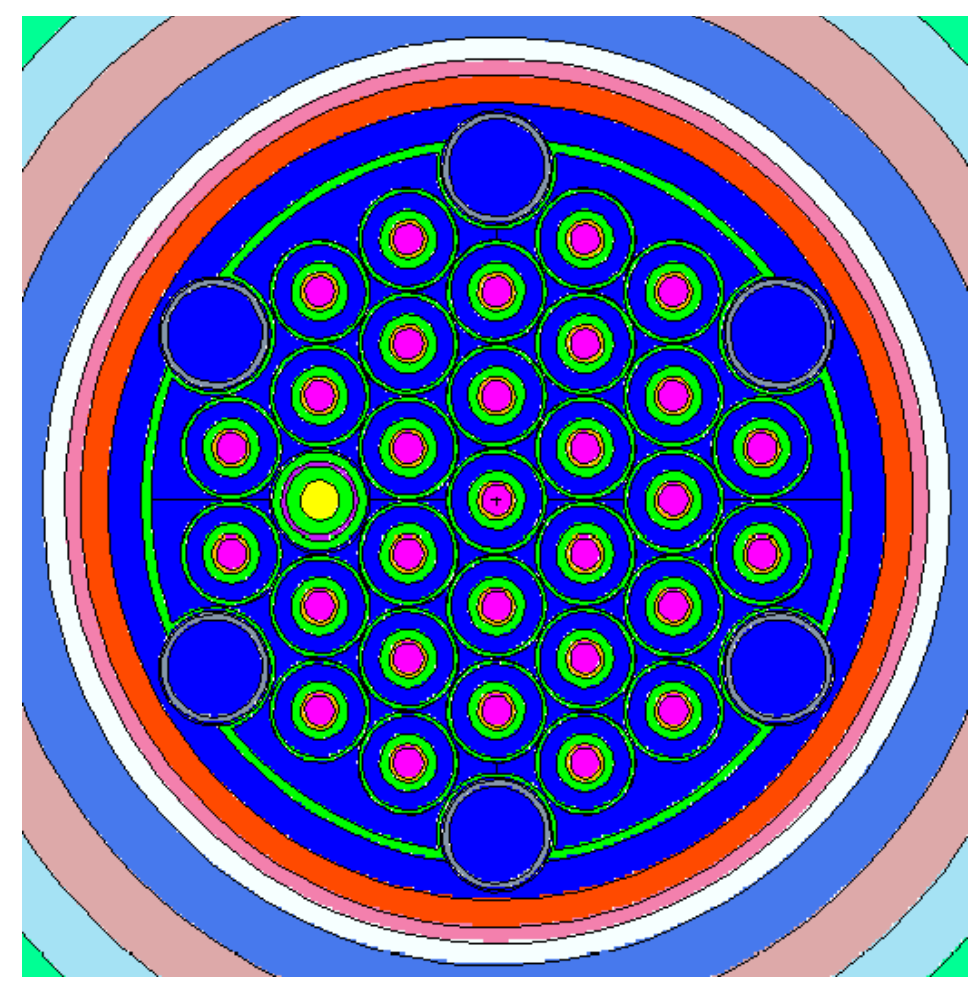

Fig. 5. Flux trap region in the LEU core model (radial view).

Table 3. Radial fuel regions in the MCNP model for HFIR LEU

\begin{tabular}{|l|c|c|c|}
\hline \multicolumn{2}{|c|}{ Inner fuel element } & \multicolumn{2}{c|}{ Outer fuel element } \\
\hline $\begin{array}{l}\text { Region } \\
\#\end{array}$ & $\begin{array}{c}\text { Outer radius } \\
(\mathrm{cm})\end{array}$ & $\begin{array}{c}\text { Region } \\
\#\end{array}$ & $\begin{array}{c}\text { Outer radius } \\
(\mathrm{cm})\end{array}$ \\
\hline $1^{a}$ & 7.50 & 1 & 15.16 \\
2 & 8.50 & 2 & 15.50 \\
3 & 9.50 & 3 & 16.50 \\
4 & 10.50 & 4 & 17.50 \\
5 & 11.50 & 5 & 18.50 \\
6 & 12.50 & 6 & 19.50 \\
7 & 12.59 & 7 & 20.50 \\
8 & 12.60 & 8 & 20.99 \\
\hline
\end{tabular}

${ }^{a}$ Inner radii are $7.14 \mathrm{~cm}$ and $15.15 \mathrm{~cm}$ for IFE and OFE, respectively. 
Table 4. Axial fuel regions in the MCNP model for HFIR LEU

\begin{tabular}{|c|c|c|c|c|c|}
\hline $\begin{array}{c}\text { Region } \\
\#\end{array}$ & $\begin{array}{c}\text { Top edge }^{a} \\
\text { location } \\
\text { (cm) }\end{array}$ & $\begin{array}{c}\text { Thickness } \\
\text { (cm) }\end{array}$ & $\begin{array}{c}\text { Region } \\
\#\end{array}$ & $\begin{array}{c}\text { Top edge } \\
\text { location } \\
\text { (cm) }\end{array}$ & $\begin{array}{c}\text { Thickness } \\
\text { (cm) }\end{array}$ \\
\hline 1 & 25.4 & 0.5 & 11 & -1 & 3.2 \\
2 & 24.9 & 0.5 & 12 & -4.2 & 8.4 \\
3 & 24.4 & 1.0 & 13 & -12.6 & 4.2 \\
4 & 23.4 & 1.0 & 14 & -16.8 & 4.2 \\
5 & 22.4 & 1.4 & 15 & -21.0 & 1.4 \\
6 & 21.0 & 4.2 & 16 & -22.4 & 1.0 \\
7 & 16.8 & 4.2 & 17 & -23.4 & 1.0 \\
8 & 12.6 & 8.4 & 18 & -24.4 & 0.5 \\
9 & 4.2 & 3.2 & 19 & -24.9 & 0.5 \\
10 & 1.0 & 2.0 & & & \\
\hline
\end{tabular}

\subsubsection{Optimization of the MCNP Model for HFIR LEU in ALEPH}

The axial layer dimensions in the Monte Carlo model in ALEPH were selected by studying trends in the thermal neutron flux and microscopic thermal fission cross section of ${ }^{235} \mathrm{U}$ as a function of radial and axial location in the fuel element. This was done to establish an optimal axial zoning of the fuel elements that would better represent the axial variation across the core of the neutron flux and fission density. A simplified 3-D MCNP model of HFIR was used for this trend study. The simplification in this model is with respect to the FTT, CR, RB, and PB regions only; the IFE and OFE regions were modelled with the same level of detail as in the model for HFIR cycle 400. Only half of the core is represented in the simplified model, from the midline to the top of the core, as illustrated in Fig. 6.

A total of 170 tally regions are defined for the fuel elements in this MCNP model: 80 regions in the IFE ( 8 radial by 10 axial) and 90 regions in the OFE ( 9 radial by 10 axial). The thicknesses of the fuel regions in the axial direction are $0.5,0.5,1.0,1.0,1.4,4.2,4.2,4.2,4.2$, and $4.2 \mathrm{~cm}$ from the top of the active fuel region to the core midline, for a total of $25.4 \mathrm{~cm}$. The values used for the radii of the regions in the fuel elements are as shown in Table 3.

The variation of the neutron thermal flux (neutron energy $<0.625 \mathrm{eV}$ ) as a function of axial location for a given radial region in the IFE and OFE is illustrated in Fig. 7. The radii specified in the legends for each of the radial regions are outer radii. The variation of the thermal flux as a function of radius for a constant axial location is shown in Fig. 8. The axial data ( $\mathrm{z}$ values) shown in the legends correspond to the lower edge of each axial layer. As can be seen, the regions at the top (or bottom) edge of the fuel elements are characterized by large leakage from fuel-bearing to non-fuel-bearing regions and by neutron flux spectra much different from the average flux in the fuel element. A more refined axial grid was therefore used for the end regions of the fuel elements to better represent the flux variation in these regions. 


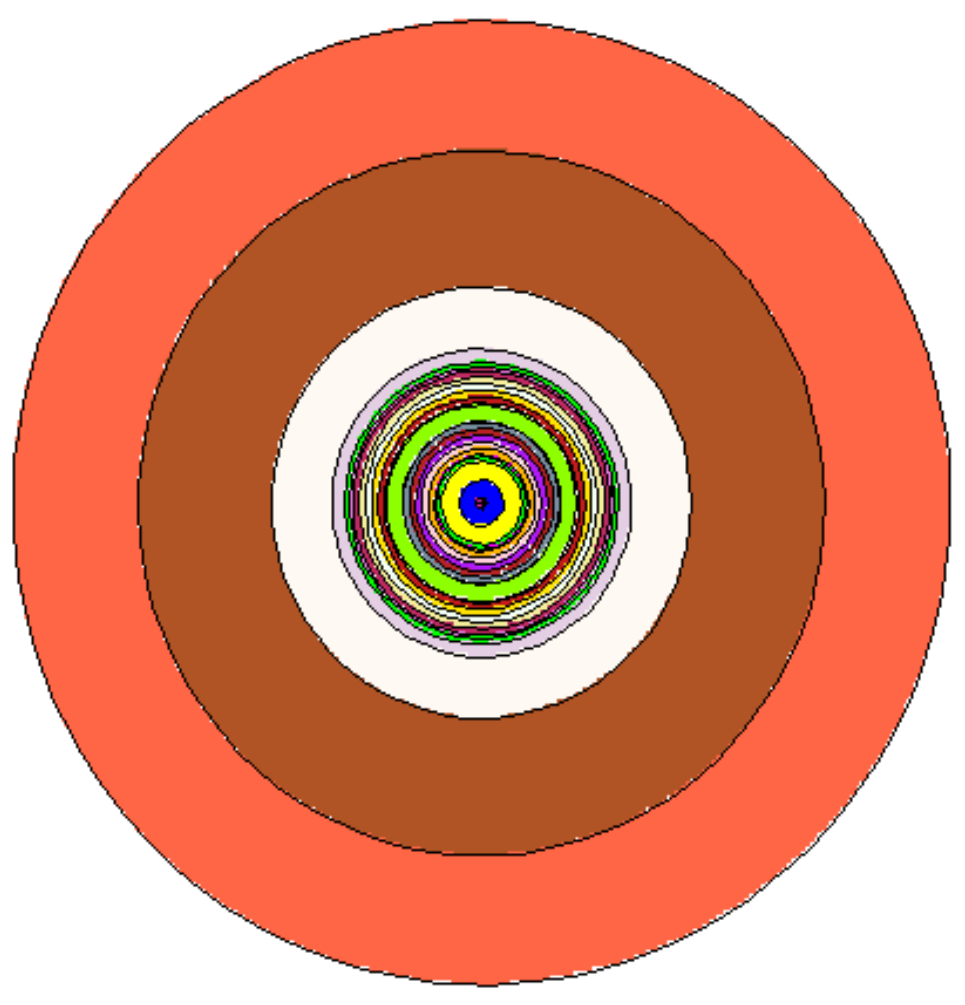

(a) radial view

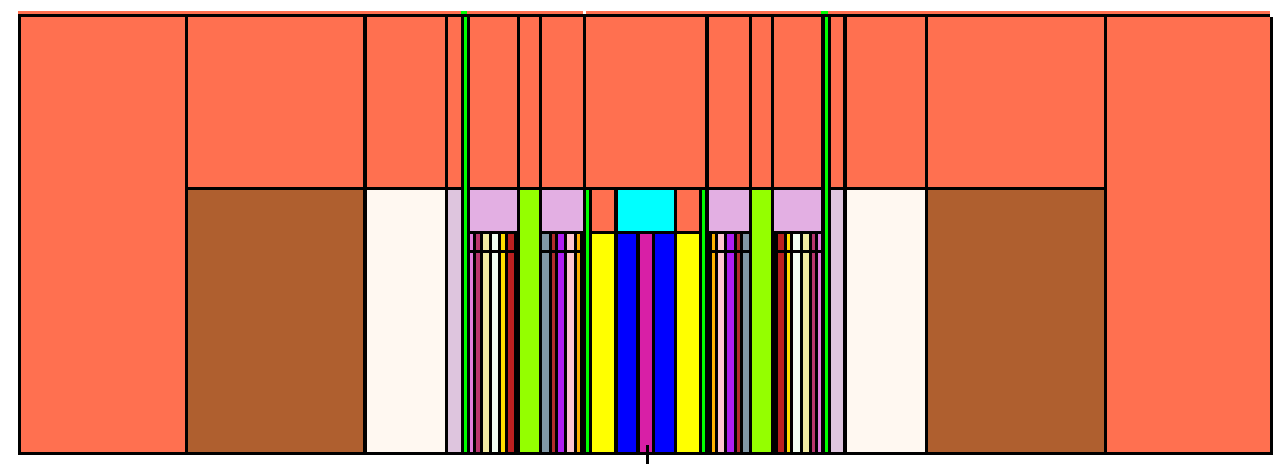

(b) axial view

Fig. 6. A 3-D MCNP simplified model for HFIR LEU. 

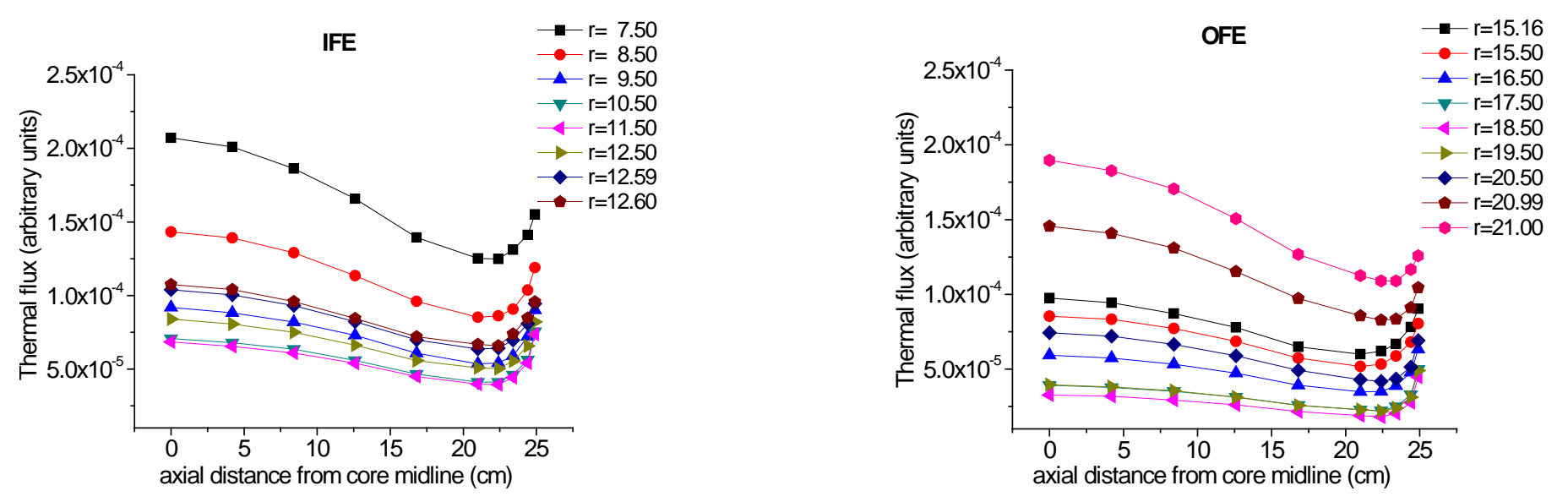

Fig. 7. Axial variation of neutron thermal flux in fuel elements.
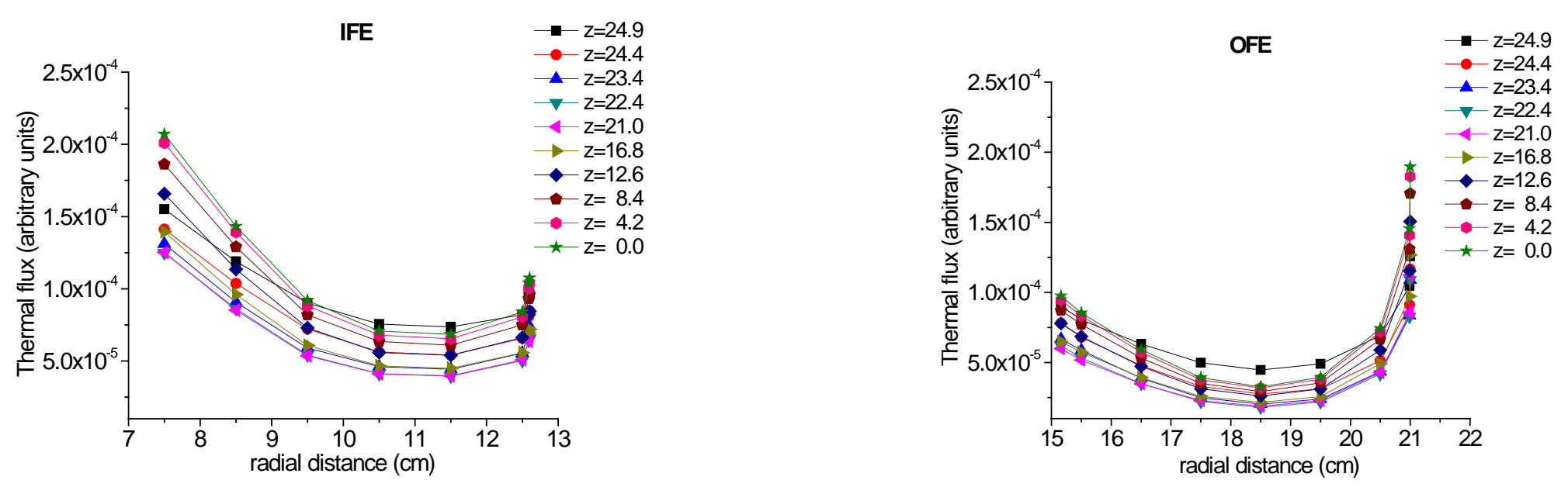

Fig. 8. Radial variation of neutron thermal flux in fuel elements. 


\subsection{DEPLETION MODEL FOR HFIR LEU IN ALEPH}

In addition to the MCNP model of the configuration to be simulated, the input data for ALEPH include information about the depletion mixtures (i.e., materials for which composition varies during simulation due to depletion and decay) and irradiation history. There are a total of 152 fuel regions in the IFE ( 8 radial by 19 axial) and 171 fuel regions ( 9 radial by 19 axial) in the OFE. For the cases with no variation of fuel composition in the axial direction, a total of 80 depletion mixtures are specified in the IFE for the purpose of flux calculation with MCNP; as previously mentioned, this flux serves to weight the pointwise cross section data to obtain the one-group cross sections for use in the ORIGEN 2.2 depletion calculation. From the 80 depletion mixtures in the IFE, 8 mixtures are specified in the central (i.e., core midline) axial layer of the IFE, one for each of the 8 radial regions. A unique depletion mixture is specified for fuel regions with the same radial region number and with the same axial distance with respect to the core midline; for example, if a region in the IFE is identified as IFE(r,z), where $r=1, \ldots, 8$ and $\mathrm{z}=1, \ldots, 19$, the same depletion mixture (i.e., material number in the MCNP input file) is used in fuel regions IFE(r,1) and IFE(r,19). Similarly, there are 90 depletion mixtures in the OFE, which gives a total of 170 depletion mixtures in the fuel elements. The material in the curium targets of the central target region is also considered a depletion mixture.

The value used for power during the irradiation was either 85 or $100 \mathrm{MW}$, as will be discussed further. The cross section libraries used in the simulation are based on data from ENDF\B-VI release 8. All cross sections were considered at $300 \mathrm{~K}$ temperature. Compared with the model for cycle 400 , the following elements- $\mathrm{Si}, \mathrm{Cr}, \mathrm{Fe}, \mathrm{Ni}$, and $\mathrm{Cu}$ - were replaced by their isotopes from ENDF/B-VI release 8, the isotopic composition being calculated based on the natural isotopic abundances for each of these elements. The elements $\mathrm{Mg}$ and Ti were also replaced by their isotopes, although in these cases data from JENDL 3.3 were used because they were missing from the ENDF\B-VI.8 data set.

ALEPH allows changes in the configuration through the use of transformation cards in the MCNP model. This permits the modeling of the control element movement during the irradiation cycle. The location of the two HFIR control elements, identified as the inner control element and the outer control element, can be changed for each of the depletion steps considered in the depletion simulation. 



\section{LEU FUEL LOAD AND GRADING}

The design of an LEU fuel that would ensure the facility capabilities are maintained at current levels can be viewed as an optimization problem with a multi-objective function (core performance parameters similar to those for the HEU core, thermal hydraulic safety margins similar to the current HEU core) with multiple constraints (no changes to fuel plate basic geometry, same number of fuel plates in fuel element). As there is no fuel shuffling and the two fuel elements are required to have the same cycle time, in HFIR the fuel management issues are addressed at the design stage.

\subsection{VARIATION OF $K_{\text {EFF }}$ AS A FUNCTION OF THE LEU FUEL LOAD}

For the first step in the search for an optimal fuel design, the fuel load in the ALEPH model of the LEU core was varied to determine the loading that would ensure a core lifetime similar to that of the HFIR HEU core. As previously mentioned, no changes in the fuel plate geometry are to be made; therefore, the maximum thickness of the fuel meat region (i.e., $762 \mu \mathrm{m}$ ) and the thickness for the fuel clad or cooling channel is the same as for the HEU fuel design. The initial LEU fuel design considered had a radial fuel grading profile as illustrated in Fig. 9 for a $17.9 \mathrm{~kg}^{235} \mathrm{U}$ load and a uniform grading in the axial direction. This initial grading was used with five values of the ${ }^{235} \mathrm{U}$ load: 17.0, 17.9, 20.0, 25.0, and $30.5 \mathrm{~kg}$. The variation of the effective multiplication constant $\left(\mathrm{k}_{\mathrm{eff}}\right)$ at the beginning-of-cycle (BOC) as a function of the total ${ }^{235} \mathrm{U}$ load is presented in Fig. 10. As observed, $\mathrm{k}_{\text {eff }}$ variation with ${ }^{235} \mathrm{U}$ load is not linear; therefore, the core lifetime (i.e., total irradiation time for which $\mathrm{k}_{\text {eff }}$ is greater than 1.0) is expected to have a similar behavior with varying amounts of ${ }^{235} \mathrm{U}$ in the core.
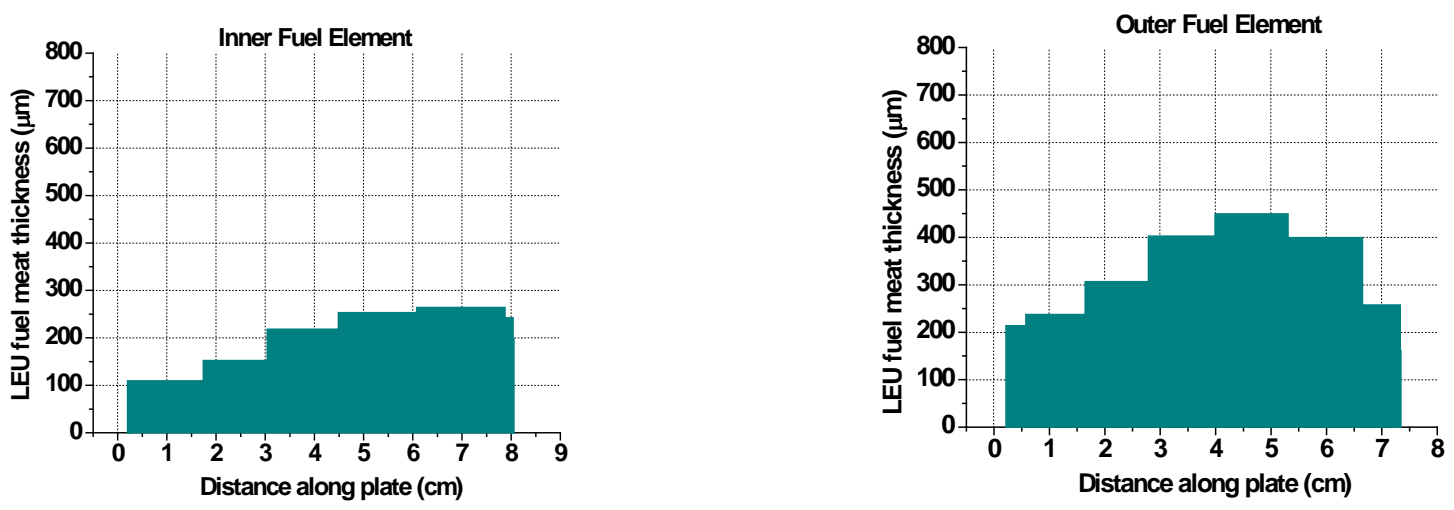

Fig. 9. Fuel plate profiles for $17.9 \mathrm{~kg}^{235} \mathrm{U}$ load.

Depletion simulations were performed with ALEPH for each of the five uranium loads. For computation speedup, seven depletion steps to reach a total irradiation time of 26 days were used. The movement of the control elements during the irradiation cycle was not simulated; the control elements were considered at their fully withdrawn end-of-cycle (EOC) locations. A value of $85 \mathrm{MW}$ was used for the operating total thermal power. The variation of $\mathrm{k}_{\mathrm{eff}}$ with the irradiation time for this fuel configuration is shown in Fig. 11 for each of the five values considered for the ${ }^{235} \mathrm{U}$ load. As seen, to reach a core lifetime of about 26 days, an initial ${ }^{235} \mathrm{U}$ load of about $25 \mathrm{~kg}$ would be necessary. The corresponding uranium load would be about $127 \mathrm{~kg}$, a large increase compared with the current HEU uranium load of $10.1 \mathrm{~kg}$. A large increase in the fuel load when converting from HEU to LEU has been reported elsewhere, regarding the Massachusetts Institute of Technology (MIT) research reactor; ${ }^{14}$ in this case, the total uranium load is expected to increase from $11.5 \mathrm{~kg}$ to $107.9 \mathrm{~kg}$. 


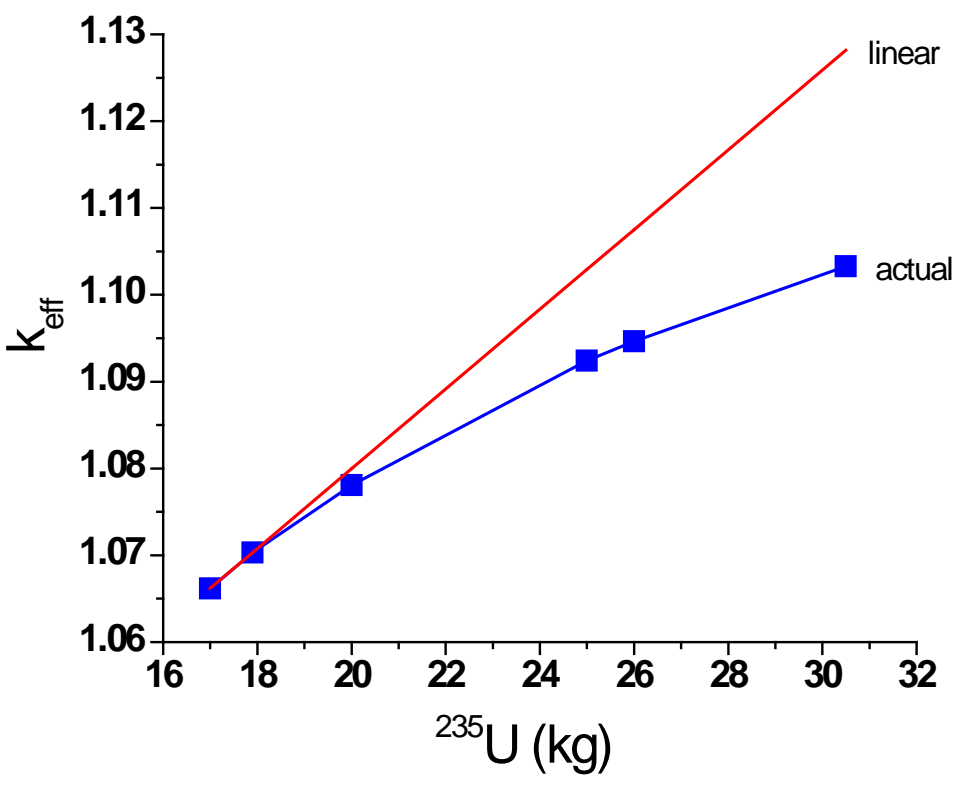

Fig. 10. Variation of $k_{\text {eff }}$ at BOC vs. initial ${ }^{235} \mathbf{U}$ load.

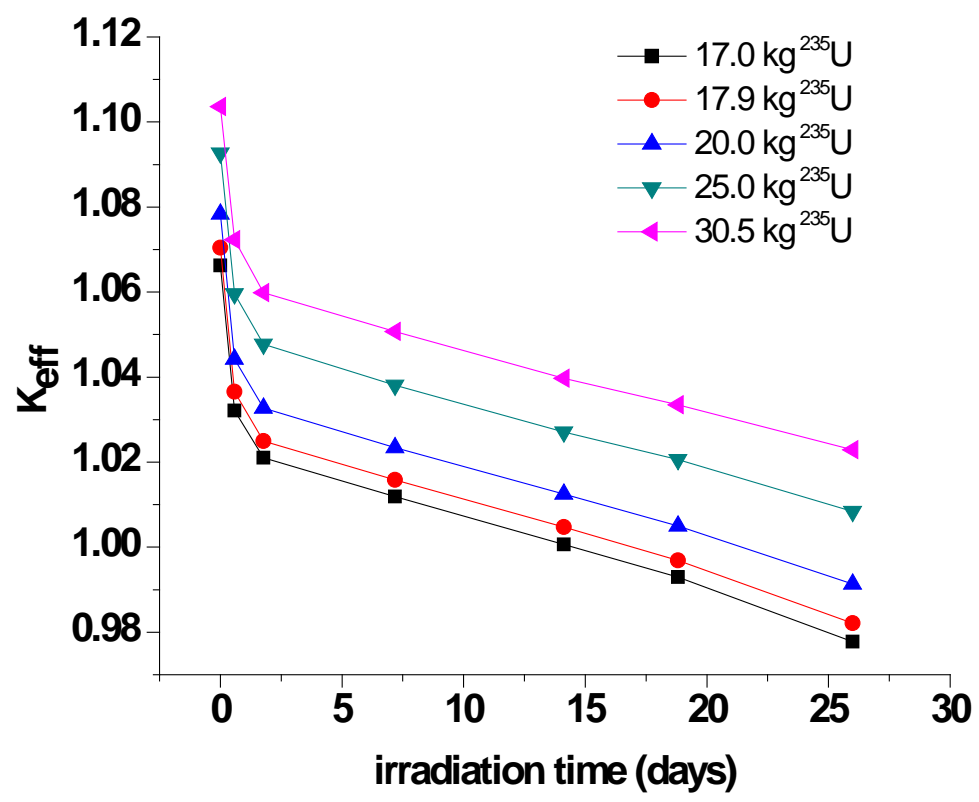

Fig. 11. Variation of $\mathbf{k}_{\text {eff }}$ during irradiation. 


\subsection{SEARCH FOR AN OPTIMAL LEU FUEL GRADING}

To test whether a proposed LEU fuel design meets the HFIR conversion requirements, the following performance parameters were studied for the LEU core and compared with their values for the current HEU core: irradiation cycle length; core power distribution; neutron flux at the central target region, reflector, and cold source location; and thermal hydraulic safety margins. As illustrated in Fig. 12, iterative reactor core physics and thermal-hydraulics calculations were performed to search for an optimal fuel load and fuel grading that would ensure a core performance similar to that of the currently operating HEU core.

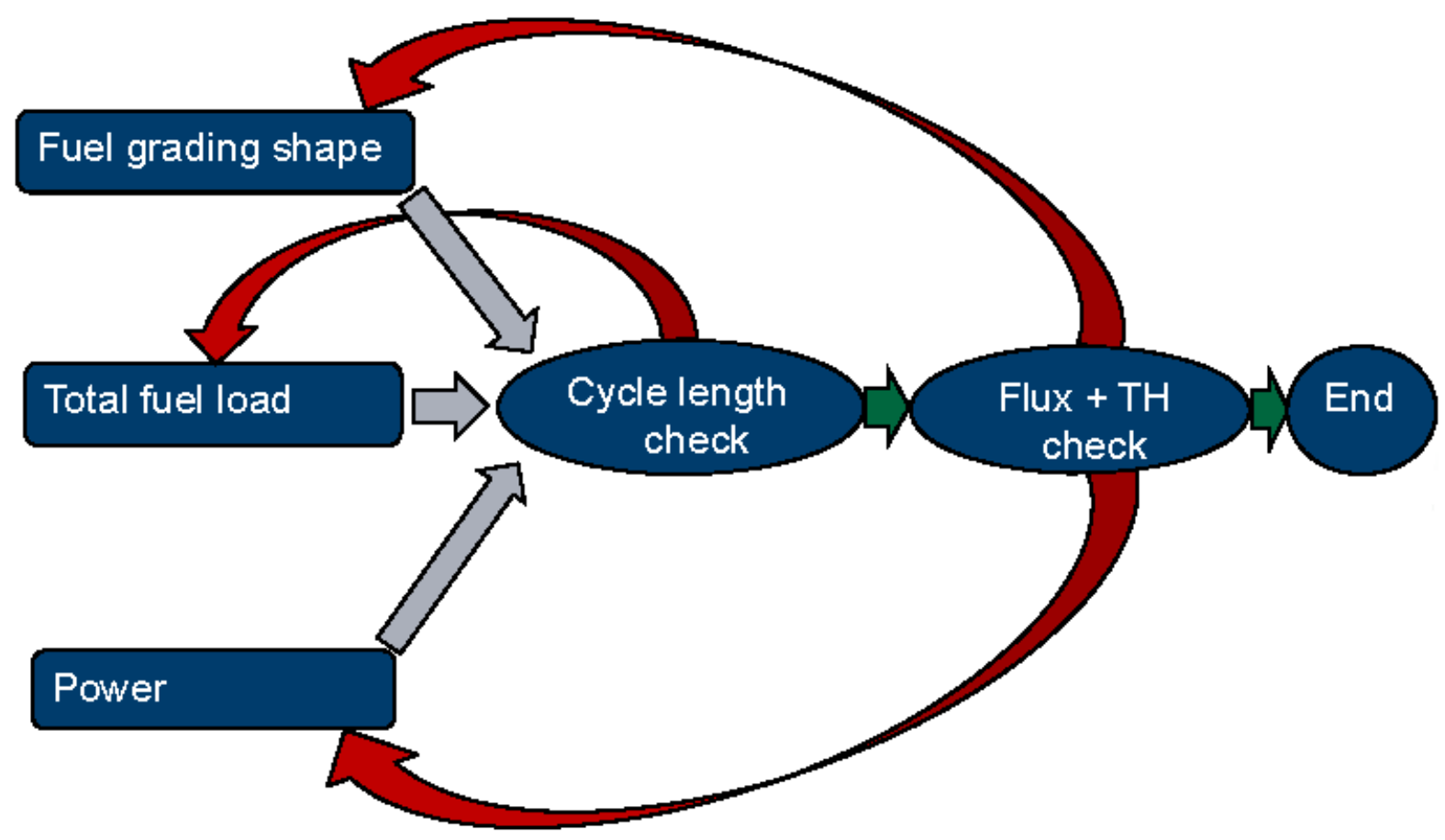

Fig. 12. Iterative search for an optimal LEU fuel design.

\subsubsection{Radial grading for the LEU fuel}

Iterations were carried out first on both total ${ }^{235} \mathrm{U}$ load and radial fuel grading profile by searching around the $25 \mathrm{~kg}$ value for the total ${ }^{235} \mathrm{U}$ load. Depletion simulations with ALEPH were performed initially for a thermal operating power of $85 \mathrm{MW}$ as used in the current HEU core. The radial grading iterations used as initial grading profile the shape illustrated in Fig. 9. To narrow the search space for the radial grading at a given uranium load, the assumed radial grading profile was tested in order to minimize the gradient in power on the radial direction, as expressed in Eq. (4-1).

$$
\sum_{1}^{J} p_{i j} v_{i j} \rightarrow 1 ; \quad i=1, I
$$

where $i j$ stands for the spatial mesh at radial location $i$ and axial location $j$ in the fuel element, $p_{i j}$ is the relative power density in spatial mesh $i j$, and $v_{i j}$ is the volume of spatial mesh $i j$. The maximum value for $j$ is $J=19$ (number of axial meshes on the axial direction) for both fuel elements, whereas the maximum value for $i, I$, is 8 for the IFE and 9 for the OFE, as used in the MCNP model of the core. 
The flux at important experiment locations was estimated and the corresponding core power distribution was applied in steady-state thermal-hydraulics analysis ${ }^{15}$ to verify whether the HEU core thermal margins were maintained. Later, the power had to be increased to $100 \mathrm{MW}$ in order to maintain the flux performance at the target locations similar to that for the HEU core at $85 \mathrm{MW}$ but still under the constraint of maintaining the same thermal margin (margin to incipient boiling) as for the HEU core at $85 \mathrm{MW}$. Axial grading was also included later because of thermal-hydraulics limits. The results of the search indicated as optimal an LEU core with a total ${ }^{235} \mathrm{U}$ load of $25.2 \mathrm{~kg}$ and a radial fuel grading profile, as illustrated in Fig. 13, and with axial grading applied to the bottom $3 \mathrm{~cm}$ of the fuel elements, as will be further discussed.
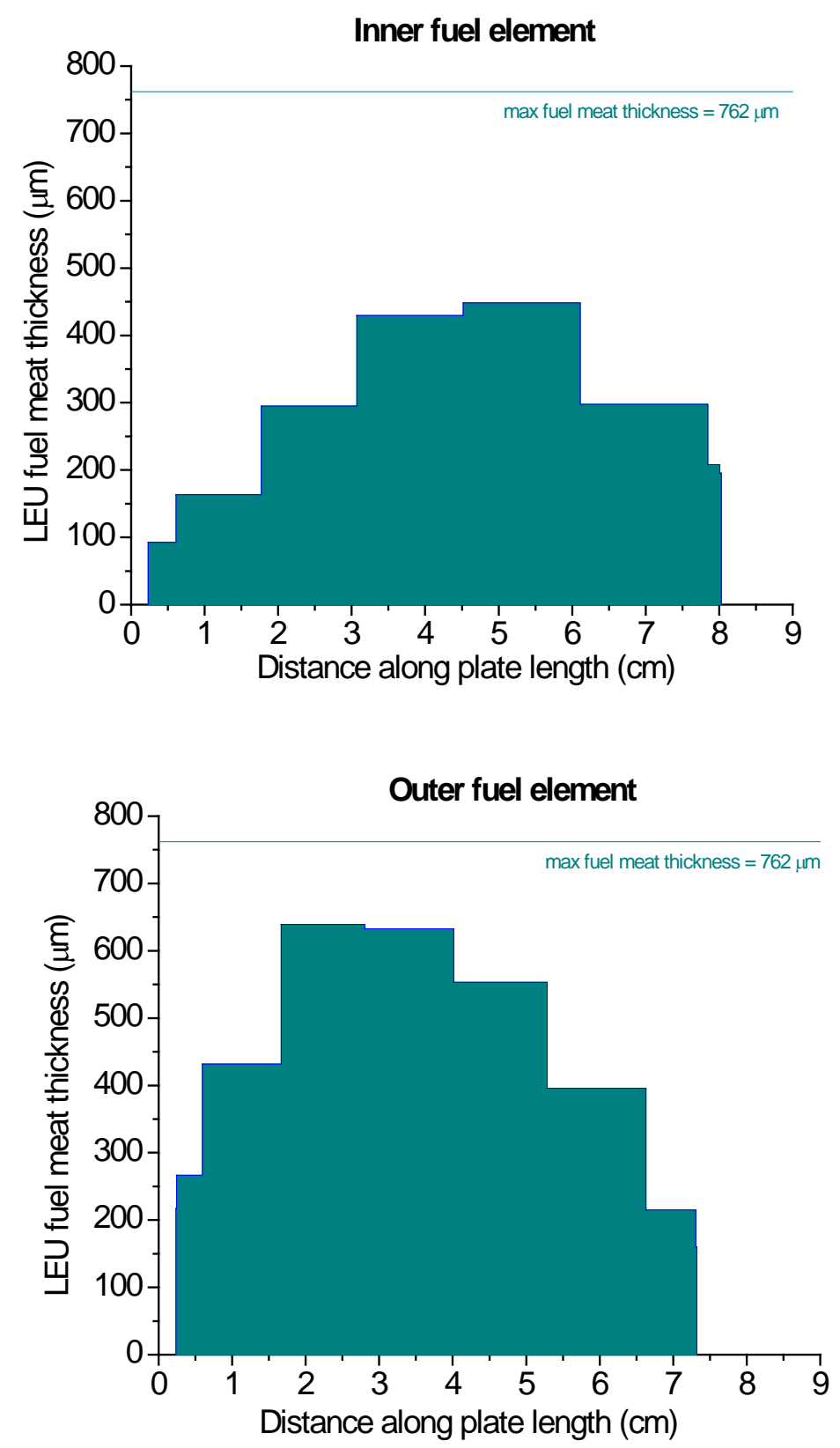

Fig. 13. Final radial grading profile for LEU fuel plates. 


\subsubsection{Axial grading for LEU fuel}

The use of axial grading at the bottom of the fuel elements was based on the observation that, as the water coolant enters the top of the core and flows from the top to the bottom of the core, the occurrence of a power "spike" at the bottom of the fuel elements would cause that location to be the point at which the margin to incipient boiling was smallest; whereas a spike at the top of the fuel elements, as it is at the location of the coolant inlet to the core, would have a much larger margin to incipient boiling. Since the margin at the bottom of the fuel was less than that currently calculated for HEU fuel, grading of the fuel at the bottom of the core was needed. The results of a thermal-hydraulics analysis showed, as discussed elsewhere, ${ }^{16}$ that the reduction of plate thickness at the bottom $3 \mathrm{~cm}$ would ensure a predicted maximum operating power at BOC of 103 MW for HFIR with LEU fuel, with the same margin-to-incipient-boiling as exists for the current HEU fuel core.
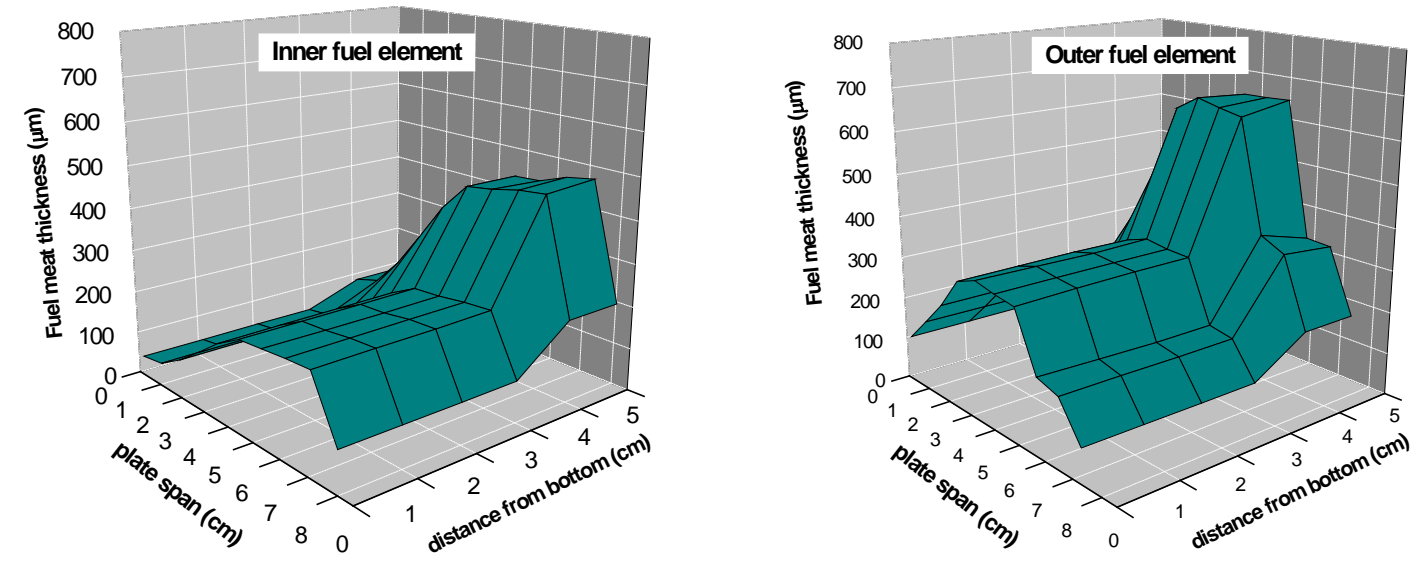

Fig. 14. Initial axial grading profiles for LEU fuel.
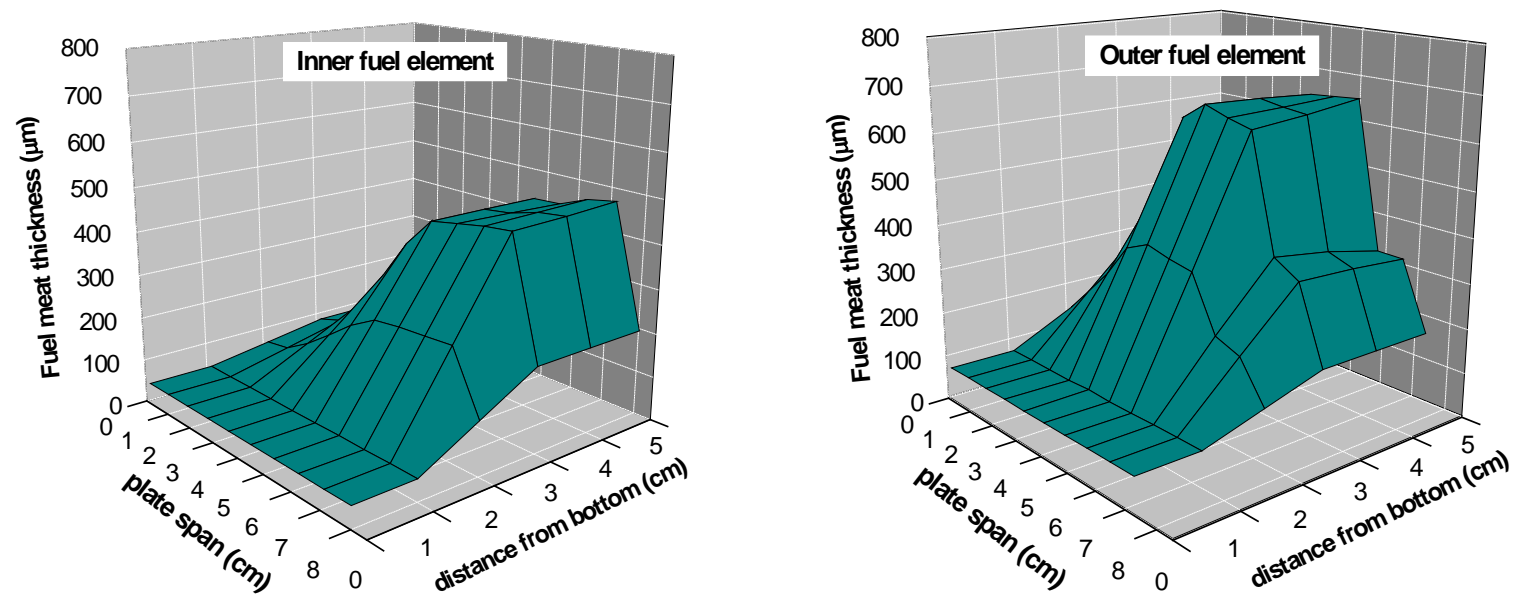

Fig. 15. Final axial grading profiles for LEU fuel.

The concentration of ${ }^{235} \mathrm{U}$ in the bottom $3 \mathrm{~cm}$ of the fuel elements for a given radial location was initially considered to be half of the value used in the other axial regions of the fuel elements for that radial location, as it is illustrated in Fig. 14. Later, two other axial grading cases were considered and applied to the bottom $2 \mathrm{~cm}$ and $1 \mathrm{~cm}$ of the fuel elements. It was found that all three cases met the thermal margins requirement. Consequently, a decision on tapering the bottom end of the fuel plates becomes a 
fabrication issue, decided by minimizing the cost of manufacturing. Later, the axial grading shape initially considered was slightly changed because a minimum plate thickness had been identified by fuel fabricators. The new shape is a flat grading on the bottom $1 \mathrm{~cm}(50 \mu \mathrm{m}$ fuel meat thickness) and a linear shape between 1 and $3 \mathrm{~cm}$ at bottom of the fuel elements.

\subsection{OPTIMAL LEU FUEL GRADING}

The radial and axial fuel grading profiles obtained from the search for an optimal grading discussed in the previous section were later slightly changed, from a smooth curve to a straight edge shape, for consistency with the proposed manufacturing process.

\subsubsection{Optimal radial grading for the LEU fuel}

For ease of manufacturing, a radial grading profile, similar to the profile used for manufacturing the current HEU fuel illustrated in Fig. 2, is proposed for the LEU fuel. However, the smooth curve illustrating the fuel meat profile for the HEU fuel plate is replaced by a three-segment shape, as illustrated in Fig. 16. The conversion from the radial grading shapes shown in Fig. 13 to the shapes shown in Fig. 16 was performed in a manner that would minimize the changes to the fuel model previously used. The fuel meat thicknesses at the plate length edges were required to be larger than a minimal thickness of $75 \mu \mathrm{m}$, and the maximum thickness (plateau) in Fig. 16 was determined by requiring that the area under the curve be conserved compared to shape shown in Fig. 13. The dimensions characterizing the obtained radial profiles are presented in Table 5.

Table 5. Radial fuel regions in the MCNP model for HFIR LEU

\begin{tabular}{|c|c|c|c|}
\hline \multicolumn{2}{|c|}{ Inner fuel element } & \multicolumn{2}{c|}{ Outer fuel element } \\
\hline $\begin{array}{c}\text { Distance along } \\
\text { plate length } \\
(\mathrm{cm})\end{array}$ & $\begin{array}{c}\text { Fuel meat } \\
\text { thickness } \\
(\mu \mathrm{m})\end{array}$ & $\begin{array}{c}\text { Distance along } \\
\text { plate length } \\
(\mathrm{cm})\end{array}$ & $\begin{array}{c}\text { Fuel meat } \\
\text { thickness } \\
(\mu \mathrm{m})\end{array}$ \\
\hline 0.231 & 75 & 0.234 & 216 \\
3.072 & 407 & 1.667 & 582 \\
6.110 & 407 & 5.286 & 582 \\
8.027 & 193 & 7.323 & 158 \\
\hline
\end{tabular}

\subsubsection{Optimal axial grading for the LEU fuel}

Axial grading was applied to the bottom $3 \mathrm{~cm}$ of the fuel plate. The difference with respect to the shapes illustrated in Fig. 15 is that the fuel thickness applied to the bottom $1 \mathrm{~cm}$ was changed from 50 to $75 \mu \mathrm{m}$, and the planes connecting the radially flat profile on the bottom $1 \mathrm{~cm}$ to the radial profile applied above $3 \mathrm{~cm}$ from the bottom (illustrated in Fig. 16) were changed accordingly. The new axial profile is illustrated in Fig. 17.

The change of the fuel grading, as discussed in this section, has a small effect on the total mass of uranium in the core, as shown in Section 4.2. The corresponding total ${ }^{235} \mathrm{U}$ core load is $25.27 \mathrm{~kg}$ and the total load of uranium is $127.95 \mathrm{~kg}$. This uranium load and shown fuel grading would ensure, as will discussed in detail later, a predicted maximum operating power at BOC of 99.4 MW. This value is consistent with the thermal power of $100 \mathrm{MW}$ used in the depletion simulation, within the accuracy of the method used for the thermal-hydraulic analysis. 

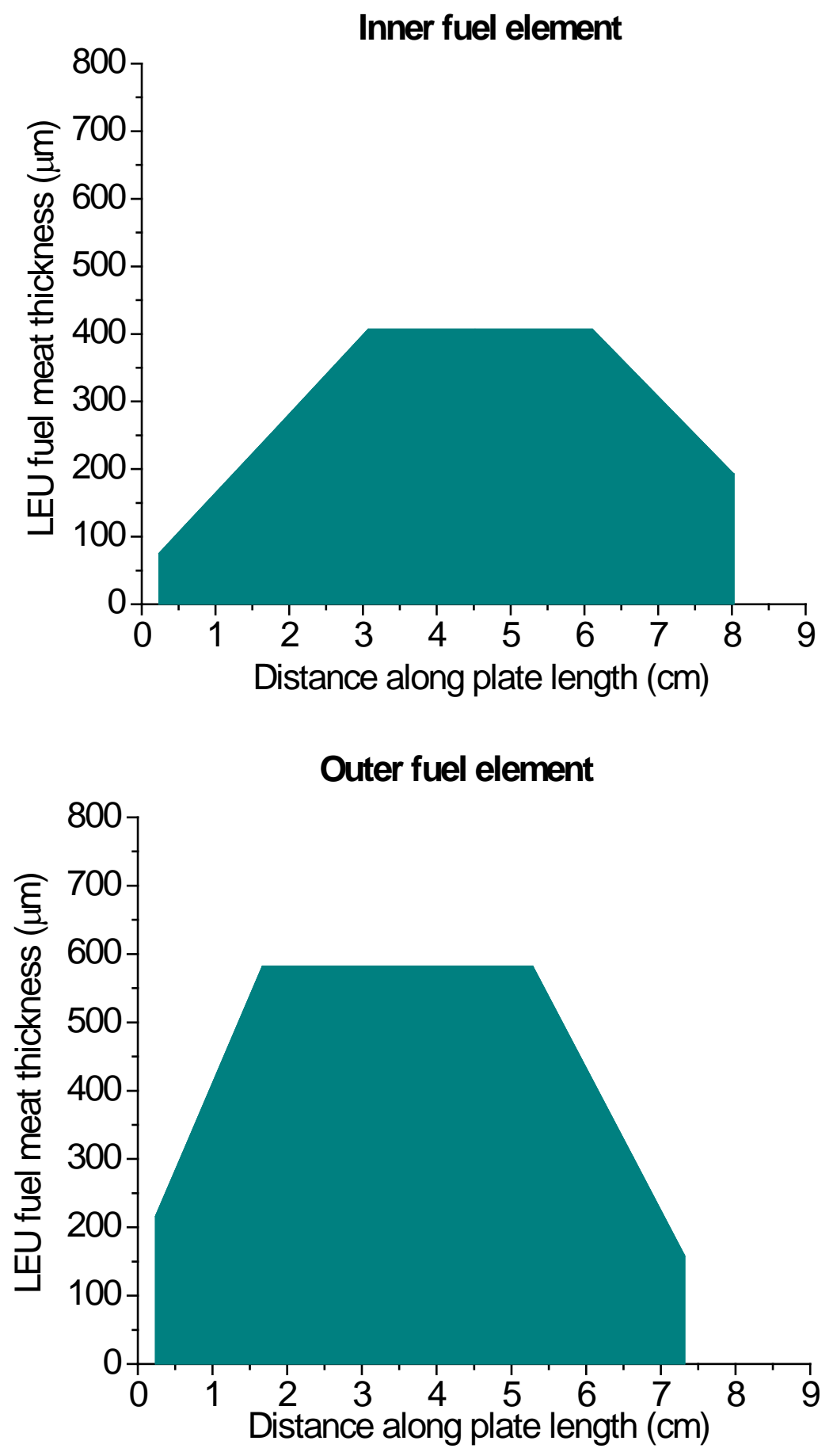

Fig. 16. Optimal radial grading profile for LEU fuel plates. 


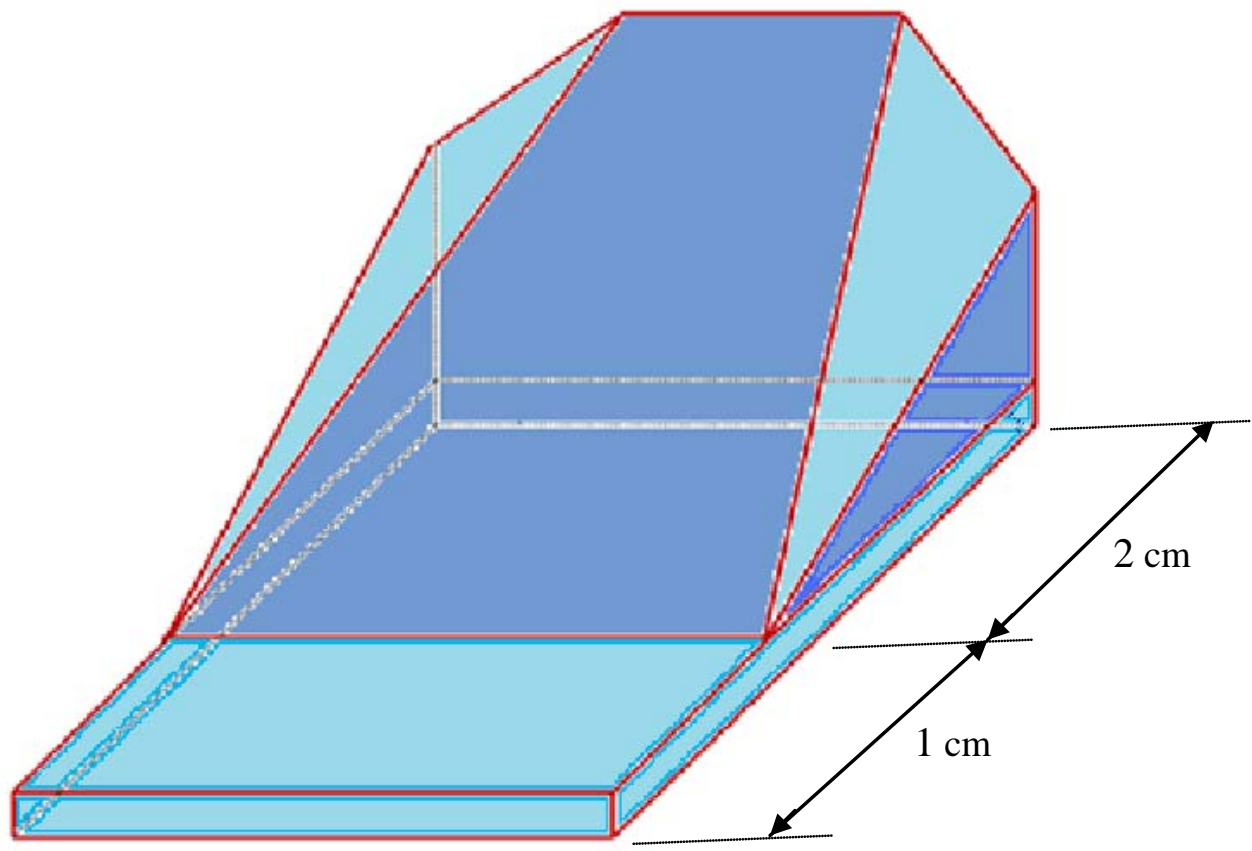

Fig. 17. Axial grading profiles for LEU fuel ( $0-3 \mathrm{~cm}$ from bottom of fuel element). 


\section{PERFORMANCE AND SAFETY PARAMETERS FOR THE HFIR LEU CORE}

Depletion simulations were carried out with ALEPH for the fuel grading and load established as discussed in Section 4.3 to calculate relevant performance parameters for the LEU core. A total of 25 depletion steps were used - 24 of one day and one of 0.33 days duration for a total of 24.33 days irradiation time- the same as for the HFIR HEU cycle 400 simulation with ALEPH. The same history of the control element movement as for cycle 400 was considered. The power used for the depletion simulation was 85 MW for the HEU cycle 400 core and 100 MW for the LEU core. Performance and safety parameters for the HFIR LEU core are presented in this section and compared with the corresponding values for the HFIR HEU cycle 400 core.

\subsection{PERFORMANCE PARAMETERS FOR THE HFIR LEU CORE}

\subsubsection{Cycle Length}

The depletion simulation for the LEU core for a cycle length of 24.33 days showed that the EOC effective multiplication factor is consistent with the value for the reference HEU cycle 400 core. The value estimated for $k_{\text {eff }}$ at EOC for the LEU core was $0.9982 \pm 0.0001$, which is in good agreement with the $0.9990 \pm 0.0002$ value obtained for the HFIR HEU cycle 400 simulation.

\subsubsection{Core Power Distribution}

The relative fission density data were calculated for each of the defined regions in the fuel elements based on flux and fission density tallies in MCNP for both BOC and EOC (at 24.33 days). These data served as input for the thermal-hydraulics analysis that showed that the corresponding operating power is 99.4 MW at BOC and 99.3 MW at EOC; these values of the power are the maximum power levels at which all thermal limits as used for the HEU core are met. The values preserve the same safety margin as exists for the current HEU fuel cycle, as documented in the HFIR Safety Analysis Report. ${ }^{17}$ The relative fission density data for the LEU core at BOC and EOC are listed in Tables 6 and 7, respectively.

\subsubsection{Peak physics parameters relevant to irradiation tests}

Fuel plate irradiations of U/Mo fuel would be expected to be conducted in the Advanced Test Reactor at Idaho National Laboratory for expected peak LEU fuel performance conditions. Table 8 provides estimates of peak fuel conditions for HFIR with U/Mo LEU fuel. The parameters included in Table 8 are: fission density, fissions per initial fissile atom (FIFA), fission rate density, and fuel plate surface heat flux. The estimates for these parameters were derived from the same calculations that generated the results in Tables 6 and 7. The volume $\left(\mathrm{cm}^{3}\right)$ corresponding to the data shown in Table 8 is the volume of U/Mo material only and not the whole plate volume or the "combined water channel and plate" volume. The reactor power level considered is $100 \mathrm{MW}$. Note that the values shown in Table 8 are nominal values, for "perfectly manufactured" fuel plates. Safety basis values would be larger than these, though the amount of change is currently unknown, since our fabrication process has not been yet quantified.

Applying current, HFIR HEU safety factors to these numbers in Table 8 would result in an increase of $42 \%(1.12 * 1.27)$ in the surface heat flux. However, it would not be correct to modify the FIFA number or the peak fission density by that factor as, for both parameters, both the numerator and denominator would be increasing. For the original HFIR HEU design, the $100 \mathrm{MW}$ HEU hot spot heat flux value was $621 \mathrm{~W} / \mathrm{cm}^{2}$; this value should include the 1.42 safety factor noted above (actually 1.43, as acceptance criteria were slightly different then). It is noteworthy that the physics design for the LEU fuel has resulted in a fuel grading profile that reduces the peak heat flux from 621 to $561 \mathrm{~W} / \mathrm{cm}^{2}$ - both values calculated using the same factor of 1.42 - about a $10 \%$ improvement. 
Table 6. Relative fission density for HFIR LEU at BOC

\begin{tabular}{|c|c|c|c|c|c|c|c|c|c|c|c|c|c|c|c|c|c|}
\hline \multirow{2}{*}{$\begin{array}{c}\text { Axial } \\
\text { region \# }\end{array}$} & \multicolumn{8}{|c|}{ IFE } & \multicolumn{9}{|c|}{ OFE } \\
\hline & $\mathrm{r}=1^{a}$ & $r=2$ & $r=3$ & $r=4$ & $r=5$ & $r=6$ & $r=7$ & $r=8$ & $\mathrm{r}=1$ & $r=2$ & $r=3$ & $r=4$ & $r=5$ & $r=6$ & $r=7$ & $r=8$ & $r=9$ \\
\hline 1 & 1.017 & 1.342 & 1.558 & 1.532 & 1.458 & 1.326 & 1.125 & 1.128 & 1.168 & 1.202 & 1.354 & 1.300 & 1.150 & 1.081 & 0.908 & 0.626 & 0.502 \\
\hline 2 & 0.885 & 1.033 & 1.032 & 0.948 & 0.930 & 0.978 & 0.937 & 0.958 & 0.986 & 0.962 & 0.924 & 0.775 & 0.673 & 0.656 & 0.640 & 0.536 & 0.462 \\
\hline 3 & 0.809 & 0.886 & 0.814 & 0.726 & 0.729 & 0.823 & 0.825 & 0.839 & 0.856 & 0.828 & 0.765 & 0.614 & 0.526 & 0.531 & 0.564 & 0.520 & 0.463 \\
\hline 4 & 0.782 & 0.839 & 0.752 & 0.672 & 0.681 & 0.769 & 0.762 & 0.778 & 0.785 & 0.766 & 0.722 & 0.590 & 0.506 & 0.520 & 0.572 & 0.544 & 0.485 \\
\hline 5 & 0.798 & 0.857 & 0.776 & 0.699 & 0.708 & 0.781 & 0.758 & 0.769 & 0.775 & 0.765 & 0.746 & 0.625 & 0.539 & 0.557 & 0.617 & 0.591 & 0.528 \\
\hline 6 & 0.908 & 0.983 & 0.901 & 0.818 & 0.827 & 0.891 & 0.845 & 0.854 & 0.862 & 0.862 & 0.865 & 0.743 & 0.647 & 0.672 & 0.749 & 0.716 & 0.639 \\
\hline 7 & 1.102 & 1.193 & 1.099 & 0.999 & 1.008 & 1.080 & 1.016 & 1.024 & 1.035 & 1.039 & 1.056 & 0.920 & 0.810 & 0.854 & 0.979 & 0.962 & 0.866 \\
\hline 8 & 1.309 & 1.418 & 1.305 & 1.190 & 1.205 & 1.293 & 1.218 & 1.229 & 1.240 & 1.247 & 1.274 & 1.118 & 0.998 & 1.083 & 1.328 & 1.393 & 1.277 \\
\hline 9 & 1.409 & 1.525 & 1.407 & 1.284 & 1.301 & 1.395 & 1.312 & 1.322 & 1.341 & 1.347 & 1.378 & 1.213 & 1.087 & 1.189 & 1.475 & 1.565 & 1.439 \\
\hline 10 & 1.413 & 1.531 & 1.410 & 1.287 & 1.306 & 1.402 & 1.320 & 1.332 & 1.344 & 1.353 & 1.384 & 1.219 & 1.092 & 1.193 & 1.482 & 1.573 & 1.448 \\
\hline 11 & 1.394 & 1.510 & 1.392 & 1.270 & 1.286 & 1.380 & 1.299 & 1.311 & 1.325 & 1.332 & 1.363 & 1.199 & 1.074 & 1.173 & 1.456 & 1.545 & 1.421 \\
\hline 12 & 1.265 & 1.371 & 1.260 & 1.148 & 1.162 & 1.244 & 1.172 & 1.183 & 1.193 & 1.198 & 1.223 & 1.071 & 0.952 & 1.027 & 1.244 & 1.290 & 1.177 \\
\hline 13 & 1.035 & 1.119 & 1.027 & 0.932 & 0.940 & 1.006 & 0.949 & 0.957 & 0.964 & 0.967 & 0.979 & 0.847 & 0.740 & 0.769 & 0.856 & 0.810 & 0.716 \\
\hline 14 & 0.849 & 0.912 & 0.829 & 0.749 & 0.757 & 0.820 & 0.781 & 0.790 & 0.797 & 0.794 & 0.790 & 0.671 & 0.581 & 0.597 & 0.656 & 0.616 & 0.543 \\
\hline 15 & 0.750 & 0.806 & 0.733 & 0.660 & 0.674 & 0.752 & 0.736 & 0.746 & 0.758 & 0.746 & 0.715 & 0.589 & 0.503 & 0.507 & 0.537 & 0.488 & 0.428 \\
\hline 16 & 0.751 & 0.835 & 0.753 & 0.723 & 0.735 & 0.752 & 0.698 & 0.701 & 0.709 & 0.732 & 0.740 & 0.631 & 0.536 & 0.517 & 0.491 & 0.397 & 0.319 \\
\hline 17 & 0.800 & 0.790 & 0.592 & 0.555 & 0.552 & 0.592 & 0.572 & 0.548 & 0.537 & 0.629 & 0.592 & 0.489 & 0.419 & 0.380 & 0.340 & 0.287 & 0.198 \\
\hline 18 & 0.720 & 0.533 & 0.414 & 0.367 & 0.355 & 0.392 & 0.457 & 0.470 & 0.445 & 0.409 & 0.333 & 0.273 & 0.236 & 0.207 & 0.179 & 0.161 & 0.158 \\
\hline 19 & 0.818 & 0.657 & 0.544 & 0.491 & 0.467 & 0.482 & 0.524 & 0.533 & 0.509 & 0.479 & 0.416 & 0.357 & 0.312 & 0.270 & 0.222 & 0.184 & 0.171 \\
\hline
\end{tabular}

${ }^{a} \mathrm{r}=\mathrm{n}$ denotes the radial region number; $\mathrm{n}$ varies from 1 to 8 for the IFE and from 1 to 9 for the OFE. 
Table 7. Relative fission density for HFIR LEU at EOC

\begin{tabular}{|c|c|c|c|c|c|c|c|c|c|c|c|c|c|c|c|c|c|}
\hline \multirow{2}{*}{$\begin{array}{c}\text { Axial } \\
\text { region \# }\end{array}$} & \multicolumn{8}{|c|}{ IFE } & \multicolumn{9}{|c|}{ OFE } \\
\hline & $\mathrm{r}=1^{a}$ & $r=2$ & $r=3$ & $r=4$ & $r=5$ & $r=6$ & $r=7$ & $r=8$ & $\mathrm{r}=1$ & $r=2$ & $r=3$ & $r=4$ & $r=5$ & $r=6$ & $r=7$ & $r=8$ & $r=9$ \\
\hline 1 & 0.760 & 1.199 & 1.540 & 1.549 & 1.494 & 1.342 & 1.082 & 1.098 & 1.153 & 1.202 & 1.487 & 1.545 & 1.488 & 1.579 & 1.605 & 1.276 & 1.069 \\
\hline 2 & 0.719 & 1.026 & 1.116 & 1.018 & 0.999 & 1.036 & 0.939 & 0.960 & 1.003 & 0.991 & 1.024 & 0.906 & 0.839 & 0.922 & 1.117 & 1.096 & 0.978 \\
\hline 3 & 0.688 & 0.910 & 0.886 & 0.771 & 0.771 & 0.864 & 0.830 & 0.855 & 0.884 & 0.854 & 0.828 & 0.686 & 0.618 & 0.694 & 0.932 & 1.004 & 0.920 \\
\hline 4 & 0.675 & 0.864 & 0.809 & 0.699 & 0.705 & 0.792 & 0.759 & 0.790 & 0.814 & 0.780 & 0.764 & 0.640 & 0.573 & 0.647 & 0.886 & 0.972 & 0.897 \\
\hline 5 & 0.685 & 0.878 & 0.823 & 0.717 & 0.721 & 0.790 & 0.745 & 0.773 & 0.791 & 0.765 & 0.772 & 0.665 & 0.599 & 0.674 & 0.908 & 0.982 & 0.903 \\
\hline 6 & 0.742 & 0.975 & 0.937 & 0.819 & 0.819 & 0.872 & 0.804 & 0.838 & 0.857 & 0.829 & 0.865 & 0.764 & 0.690 & 0.770 & 1.008 & 1.044 & 0.951 \\
\hline 7 & 0.823 & 1.130 & 1.110 & 0.968 & 0.964 & 1.010 & 0.919 & 0.963 & 0.986 & 0.950 & 1.009 & 0.898 & 0.811 & 0.903 & 1.158 & 1.146 & 1.028 \\
\hline 8 & 0.883 & 1.273 & 1.285 & 1.117 & 1.109 & 1.153 & 1.039 & 1.098 & 1.123 & 1.077 & 1.154 & 1.029 & 0.929 & 1.034 & 1.311 & 1.256 & 1.117 \\
\hline 9 & 0.904 & 1.333 & 1.365 & 1.187 & 1.175 & 1.216 & 1.092 & 1.157 & 1.186 & 1.135 & 1.222 & 1.090 & 0.983 & 1.093 & 1.381 & 1.304 & 1.156 \\
\hline 10 & 0.903 & 1.338 & 1.371 & 1.192 & 1.181 & 1.220 & 1.094 & 1.159 & 1.189 & 1.136 & 1.225 & 1.094 & 0.987 & 1.097 & 1.385 & 1.307 & 1.159 \\
\hline 11 & 0.897 & 1.324 & 1.356 & 1.178 & 1.167 & 1.211 & 1.085 & 1.149 & 1.179 & 1.127 & 1.214 & 1.083 & 0.978 & 1.089 & 1.375 & 1.299 & 1.151 \\
\hline 12 & 0.866 & 1.248 & 1.259 & 1.096 & 1.087 & 1.130 & 1.019 & 1.076 & 1.099 & 1.054 & 1.131 & 1.010 & 0.912 & 1.015 & 1.288 & 1.235 & 1.098 \\
\hline 13 & 0.794 & 1.089 & 1.068 & 0.930 & 0.926 & 0.973 & 0.887 & 0.932 & 0.952 & 0.916 & 0.971 & 0.864 & 0.781 & 0.870 & 1.119 & 1.112 & 0.997 \\
\hline 14 & 0.716 & 0.939 & 0.895 & 0.780 & 0.781 & 0.840 & 0.781 & 0.815 & 0.833 & 0.803 & 0.829 & 0.726 & 0.656 & 0.735 & 0.970 & 1.012 & 0.922 \\
\hline 15 & 0.677 & 0.869 & 0.825 & 0.721 & 0.730 & 0.817 & 0.779 & 0.808 & 0.830 & 0.798 & 0.793 & 0.674 & 0.605 & 0.680 & 0.914 & 0.984 & 0.908 \\
\hline 16 & 0.689 & 0.922 & 0.885 & 0.834 & 0.845 & 0.848 & 0.753 & 0.766 & 0.780 & 0.802 & 0.857 & 0.768 & 0.701 & 0.778 & 0.967 & 0.971 & 0.832 \\
\hline 17 & 0.715 & 0.852 & 0.696 & 0.660 & 0.654 & 0.671 & 0.612 & 0.590 & 0.584 & 0.685 & 0.700 & 0.632 & 0.601 & 0.643 & 0.764 & 0.842 & 0.650 \\
\hline 18 & 0.603 & 0.527 & 0.450 & 0.409 & 0.399 & 0.427 & 0.470 & 0.486 & 0.466 & 0.430 & 0.378 & 0.345 & 0.338 & 0.354 & 0.407 & 0.498 & 0.561 \\
\hline 19 & 0.631 & 0.580 & 0.526 & 0.493 & 0.479 & 0.490 & 0.516 & 0.529 & 0.510 & 0.484 & 0.453 & 0.432 & 0.430 & 0.445 & 0.488 & 0.554 & 0.602 \\
\hline
\end{tabular}

${ }^{a} \mathrm{r}=\mathrm{n}$ denotes the radial region number; $\mathrm{n}$ varies from 1 to 8 for the IFE and from 1 to 9 for the OFE.

Table 8. Peak performance parameters for LEU fuel in HFIR

\begin{tabular}{|l|c|l|}
\hline Parameter & \multicolumn{1}{|c|}{ Value } & Comments \\
\hline fission density & $3.69\left(10^{21}\right)$ fissions/( $\left.\mathrm{cm}^{3} \mathrm{U} / \mathrm{Mo}\right)$ & A HFIR fuel plate has both fuel and filler regions \\
\hline $\begin{array}{l}\text { fissions per initial fissile atom } \\
\text { (FIFA) }\end{array}$ & 0.476 & Different units, same location and burnup as fission density \\
\hline fission rate density & $2.37\left(10^{15}\right)$ fissions $/\left(\mathrm{cm}^{3} * \mathrm{~s}\right)$ & The volume considered is the U/Mo fuel region \\
\hline fuel plate surface heat flux & $395 \mathrm{~W} / \mathrm{cm}^{2}$ & $\begin{array}{l}\text { Due to varying fuel thickness, the peak surface heat flux } \\
\text { differs from the peak fission rate density }\end{array}$ \\
\hline
\end{tabular}




\subsubsection{Neutron Flux}

As mentioned previously, the neutron flux level, one of the key parameters for characterizing core performance, should be maintained when replacing HEU with LEU so that facility missions will not be affected. A comparison of three-group flux data estimated based on MCNP flux tallies for the current HEU core at $85 \mathrm{MW}$ power and the proposed LEU core at $100 \mathrm{MW}$ power at BOC and EOC, respectively, is presented in Tables 9 and 10. The relative standard deviation for the tallied flux is less than $1 \%$ in all cases. The energy structure for the shown three-group data is thermal $<0.625 \mathrm{eV}$; epithermal $0.625 \mathrm{eV}-100 \mathrm{keV}$; and fast $100 \mathrm{keV}-20 \mathrm{MeV}$. As the flux tallies provided by MCNP are normalized to the source (i.e., 1 fission neutron), the values for the flux in $\mathrm{n} / \mathrm{cm}^{2} \mathrm{~s}$ were obtained by multiplying the flux tally values by the total source. The total source $S$ was approximated as ${ }^{13}$

$$
S=\frac{\gamma P}{E e}
$$

where $v$ is the average number of neutrons per fission, $P$ is the reactor power in MW, $E$ is the average energy per fission in $\mathrm{MeV}$, and $e$ is a conversion factor. An approximate value of $200 \mathrm{MeV}$ was used for $E$, whereas the value for $v$ was taken directly from the MCNP output. The value of the total source at BOC is $6.47 \times 10^{18} \mathrm{n} / \mathrm{s}$ for HEU at $85 \mathrm{MW}$ power and $7.65 \times 10^{18} \mathrm{n} / \mathrm{s}$ for LEU at $100 \mathrm{MW}$ power. The flux is shown for three important experiment locations: the central target in the flux trap, the edge of the cold source, and the beryllium reflector at $27 \mathrm{~cm}$ from the center at core midline. As observed, the fluxes corresponding to the LEU core are comparable to those for the HEU core.

Table 9. Neutron flux at BOC—comparison of HEU cycle 400 and LEU cores

\begin{tabular}{|c|c||c|c||c|}
\hline Location & Fuel & $\begin{array}{c}\text { Thermal flux } \\
\left(\mathrm{n} / \mathrm{cm}^{2} \mathrm{~s}\right)\end{array}$ & $\begin{array}{c}\text { Epithermal flux } \\
\left(\mathrm{n} / \mathrm{cm}^{2} \mathrm{~s}\right)\end{array}$ & $\begin{array}{c}\text { Fast flux } \\
\left(\mathrm{n} / \mathrm{cm}^{2} \mathrm{~s}\right)\end{array}$ \\
\hline \multirow{2}{*}{ Central target } & HEU & $\begin{array}{l}2.2 \times 10^{15} \\
2.3 \times 10^{15}\end{array}$ & $\begin{array}{l}1.3 \times 10^{15} \\
1.3 \times 10^{15}\end{array}$ & $\begin{array}{l}1.1 \times 10^{15} \\
1.1 \times 10^{15}\end{array}$ \\
\hline \multirow{2}{*}{ Cold source edge } & HEU & $6.8 \times 10^{14}$ & $2.4 \times 10^{14}$ & $9.0 \times 10^{13}$ \\
& LEU & $8.2 \times 10^{14}$ & $2.9 \times 10^{14}$ & $1.0 \times 10^{14}$ \\
\hline \multirow{2}{*}{ Reflector $\mathrm{r}=27 \mathrm{~cm}$} & HEU & $6.0 \times 10^{14}$ & $6.5 \times 10^{14}$ & $4.1 \times 10^{14}$ \\
& LEU & $7.0 \times 10^{14}$ & $7.7 \times 10^{14}$ & $4.8 \times 10^{14}$ \\
\hline
\end{tabular}

Table 10. Neutron flux at EOC_comparison of HEU cycle 400 and LEU cores

\begin{tabular}{|c|c||c|c||c|}
\hline Location & Fuel & $\begin{array}{c}\text { Thermal flux } \\
\left(\mathrm{n} / \mathrm{cm}^{2} \mathrm{~s}\right)\end{array}$ & $\begin{array}{c}\text { Epithermal flux } \\
\left(\mathrm{n} / \mathrm{cm}^{2} \mathrm{~s}\right)\end{array}$ & $\begin{array}{c}\text { Fast flux } \\
\left(\mathrm{n} / \mathrm{cm}^{2} \mathrm{~s}\right)\end{array}$ \\
\hline \multirow{3}{*}{ Central target } & HEU & $\begin{array}{l}2.3 \times 10^{15} \\
2.5 \times 10^{15}\end{array}$ & $\begin{array}{l}1.1 \times 10^{15} \\
1.2 \times 10^{15}\end{array}$ & $\begin{array}{l}9.9 \times 10^{14} \\
1.0 \times 10^{15}\end{array}$ \\
\hline \multirow{2}{*}{ Lold source edge } & HEU & $8.3 \times 10^{14}$ & $2.4 \times 10^{14}$ & $8.9 \times 10^{13}$ \\
& LEU & $8.5 \times 10^{14}$ & $2.8 \times 10^{14}$ & $1.0 \times 10^{14}$ \\
\hline & HEU & $8.1 \times 10^{14}$ & $6.5 \times 10^{14}$ & $4.0 \times 10^{14}$ \\
$7.3 \times 10^{14}$ & $7.5 \times 10^{14}$ & $4.6 \times 10^{14}$ \\
\hline
\end{tabular}




\subsection{SAFETY AND SAFEGUARDS PARAMETERS FOR THE HFIR LEU CORE}

\subsubsection{Decay Heat in Used Fuel Elements}

A procedure was developed to extract the depleted fuel composition data from the ALEPH output and feed it into the ORIGEN-ARP sequence in SCALE for source term characterization. The total mass of used fuel from the core (as a sum of the IFE and OFE compositions) was considered as one source. The calculated decay heat for the used LEU fuel corresponding to the normal discharge time (i.e., 1 day after shutdown) and to 1, 3, 10, 30, and 100 years cooling time is presented in Table 11. In addition to the total decay heat value, the component of the decay heat due to the actinides present in the used fuel is shown. A comparison of the total decay heat from LEU and HEU used fuel as a function of the decay time is shown in Fig. 18.

Table 11. Decay heat for used fuel-comparison of HEU cycle 400 and $L E U$ cores

\begin{tabular}{|l|c|c|c|c|}
\hline \multirow{2}{*}{ Decay time (year) } & \multicolumn{2}{|c|}{ Total decay heat (W) } & \multicolumn{2}{c|}{ Actinides decay heat (W) } \\
\cline { 2 - 5 } & LEU & HEU & LEU & HEU \\
\hline Discharge & $3.12 \times 10^{5}$ & $2.45 \times 10^{5}$ & $3.47 \times 10^{4}$ & $2.19 \times 10^{3}$ \\
\hline 1 & $1.50 \times 10^{3}$ & $1.28 \times 10^{3}$ & $1.43 \times 10^{0}$ & $2.91 \times 10^{-1}$ \\
\hline 3 & $2.65 \times 10^{2}$ & $2.26 \times 10^{2}$ & $1.49 \times 10^{0}$ & $2.92 \times 10^{-1}$ \\
\hline 10 & $7.42 \times 10^{1}$ & $6.35 \times 10^{1}$ & $1.68 \times 10^{0}$ & $2.96 \times 10^{-1}$ \\
\hline 30 & $4.52 \times 10^{1}$ & $3.79 \times 10^{1}$ & $1.96 \times 10^{0}$ & $2.90 \times 10^{-1}$ \\
\hline 100 & $1.00 \times 10^{1}$ & $7.20 \times 10^{0}$ & $1.98 \times 10^{0}$ & $2.21 \times 10^{-1}$ \\
\hline
\end{tabular}

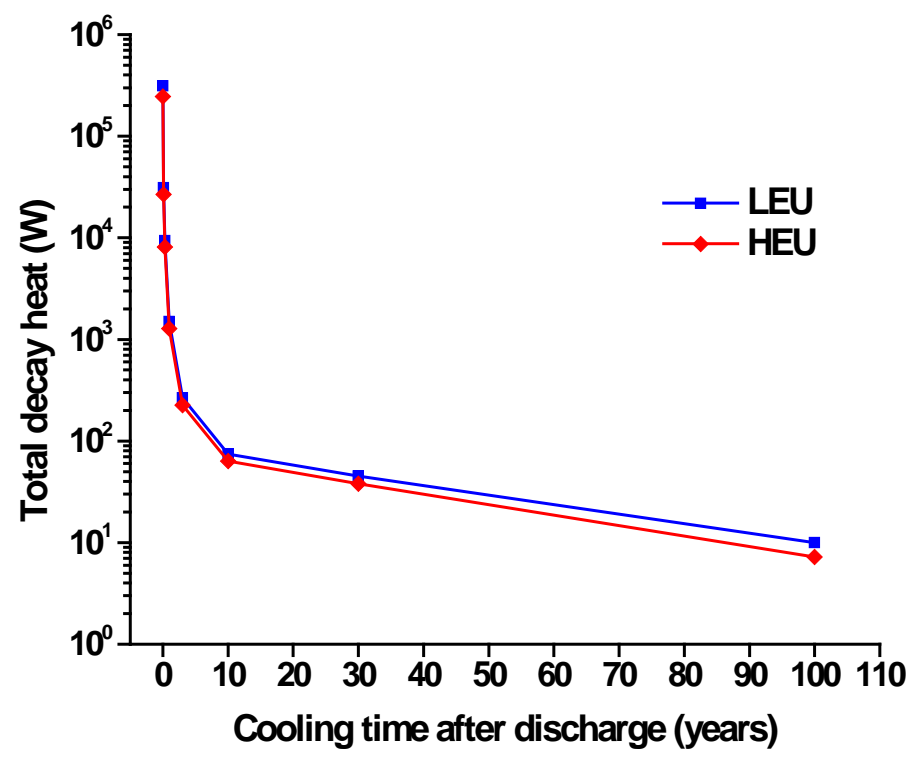

Fig. 18. Decay heat for used fuel—comparison of HEU cycle 400 and LEU cores. 
The total decay heat for LEU fuel is slightly larger than the corresponding value for the HEU fuel, as expected, given the larger production of transuranic nuclides in the LEU than in the HEU fuel. At 10 years cooling time, the total decay heat decreases by almost four orders of magnitude, becoming less than $100 \mathrm{~W}$, and becomes less than $10 \mathrm{~W}$ after 100 years of decay. The top 20 nuclides contributing to the decay heat at discharge and the corresponding decay heat for the HEU and LEU core are shown in Table 12.

Table 12. Major contributors to total decay heat at discharge-comparison of HEU cycle 400 and LEU cores

\begin{tabular}{|c|c|c|c|c|}
\hline & \multicolumn{2}{|c|}{ HEU } & \multicolumn{2}{c|}{ LEU } \\
\hline$\#$ & Nuclide ID & Decay heat (W) & Nuclide ID & Decay heat (W) \\
\hline 1 & ${ }^{140} \mathrm{La}$ & $5.19 \mathrm{E}+04$ & ${ }^{140} \mathrm{La}$ & $5.99 \mathrm{E}+04$ \\
\hline 2 & ${ }^{132} \mathrm{I}$ & $4.18 \mathrm{E}+04$ & ${ }^{132} \mathrm{I}$ & $4.87 \mathrm{E}+04$ \\
\hline 3 & ${ }^{133} \mathrm{I}$ & $1.32 \mathrm{E}+04$ & ${ }^{239} \mathrm{~Np}$ & $3.35 \mathrm{E}+04$ \\
\hline 4 & ${ }^{99} \mathrm{Mo}$ & $1.32 \mathrm{E}+04$ & ${ }^{99} \mathrm{Mo}$ & $1.52 \mathrm{E}+04$ \\
\hline 5 & ${ }^{143} \mathrm{Ce}$ & $1.07 \mathrm{E}+04$ & ${ }^{133} \mathrm{I}$ & $1.48 \mathrm{E}+04$ \\
\hline 6 & ${ }^{97} \mathrm{Nb}$ & $1.05 \mathrm{E}+04$ & ${ }^{143} \mathrm{Ce}$ & $1.19 \mathrm{E}+04$ \\
\hline 7 & ${ }^{140} \mathrm{Ba}$ & $8.93 \mathrm{E}+03$ & ${ }^{97} \mathrm{Nb}$ & $1.16 \mathrm{E}+04$ \\
\hline 8 & ${ }^{97} \mathrm{Zr}$ & $8.18 \mathrm{E}+03$ & ${ }^{140} \mathrm{Ba}$ & $1.03 \mathrm{E}+04$ \\
\hline 9 & ${ }^{93} \mathrm{Y}$ & $6.62 \mathrm{E}+03$ & ${ }^{97} \mathrm{Zr}$ & $9.05 \mathrm{E}+03$ \\
\hline 10 & ${ }^{97} \mathrm{Nb}$ & $6.51 \mathrm{E}+03$ & ${ }^{97 m} \mathrm{Nb}$ & $7.20 \mathrm{E}+03$ \\
\hline 11 & ${ }^{131} \mathrm{I}$ & $5.73 \mathrm{E}+03$ & ${ }^{93} \mathrm{Y}$ & $7.02 \mathrm{E}+03$ \\
\hline 12 & ${ }^{91} \mathrm{Sr}$ & $5.73 \mathrm{E}+03$ & ${ }^{131} \mathrm{I}$ & $6.76 \mathrm{E}+03$ \\
\hline 13 & ${ }^{95} \mathrm{Zr}$ & $5.25 \mathrm{E}+03$ & ${ }^{143} \mathrm{Pr}$ & $6.07 \mathrm{E}+03$ \\
\hline 14 & ${ }^{143} \mathrm{Pr}$ & $5.20 \mathrm{E}+03$ & ${ }^{95} \mathrm{Zr}$ & $6.07 \mathrm{E}+03$ \\
\hline 15 & ${ }^{132} \mathrm{Te}$ & $4.88 \mathrm{E}+03$ & ${ }^{91} \mathrm{Sr}$ & $5.99 \mathrm{E}+03$ \\
\hline 16 & ${ }^{133} \mathrm{Xe}$ & $4.61 \mathrm{E}+03$ & ${ }^{132} \mathrm{Te}$ & $5.69 \mathrm{E}+03$ \\
\hline 17 & ${ }^{135} \mathrm{I}$ & $4.11 \mathrm{E}+03$ & ${ }^{133} \mathrm{Xe}$ & $5.46 \mathrm{E}+03$ \\
\hline 18 & ${ }^{91} \mathrm{Y}$ & $3.75 \mathrm{E}+03$ & ${ }^{135} \mathrm{I}$ & $4.31 \mathrm{E}+03$ \\
\hline 19 & ${ }^{89} \mathrm{Sr}$ & $3.27 \mathrm{E}+03$ & ${ }^{91} \mathrm{Y}$ & $4.29 \mathrm{E}+03$ \\
\hline 20 & ${ }^{135} \mathrm{Xe}$ & $3.25 \mathrm{E}+03$ & ${ }^{135} \mathrm{Xe}$ & $3.74 \mathrm{E}+03$ \\
\hline
\end{tabular}




\subsubsection{Isotopic Compositions in Used Fuel Elements}

The isotopic composition of the used fuel, which is important to safeguards, reactor safety, and waste management, the plutonium inventory in particular, is another core parameter to be assessed for the LEU fuel. A comparison of the HEU and LEU cores with respect to the total mass in the core at EOC for the main actinides uranium and plutonium is presented in Table 13. As expected, the production of plutonium increases, given the large fraction of ${ }^{238} \mathrm{U}$ present in the LEU fuel. The total amount of plutonium at EOC is about $14 \mathrm{~g}$ for the HEU core and $430 \mathrm{~g}$ for the LEU core.

Table 13. Major actinides inventory for HEU and LEU cores at EOC

\begin{tabular}{|l|r|r|}
\hline Nuclide & $\begin{array}{c}\text { HEU core } \\
\text { (g) }\end{array}$ & \multicolumn{1}{c|}{$\begin{array}{c}\text { LEU core } \\
\text { (g) }\end{array}$} \\
\hline U-234 & 88.04 & 232.1 \\
\hline U-235 & 6785.29 & 22251.7 \\
\hline U-236 & 502.33 & 741.2 \\
\hline U-238 & 531.98 & 101699.0 \\
\hline Pu-238 & 0.27 & 0.6 \\
\hline Pu-239 & 11.40 & 391.9 \\
\hline Pu-240 & 1.43 & 25.4 \\
\hline Pu-241 & 0.61 & 8.1 \\
\hline Pu-242 & 0.05 & 2.8 \\
\hline
\end{tabular}





\section{SUMMARY AND CONCLUSIONS}

The computational models used to search for an LEU fuel design that would meet the requirements for the HEU to LEU conversion study, and the results obtained with these models during FY 2009, are documented and discussed in this report. Estimates of relevant reactor performance parameters for the LEU fuel core are presented and compared with the corresponding data for the currently operating HEU fuel core. No degradation of the HFIR performance parameters was observed as result of the change of the fuel to LEU.

The LEU fuel design considered has 2-D grading, both radial and axial, with the axial grading applied only to the bottom $3 \mathrm{~cm}$ of the fuel elements. Additional changes to this design will be made, using the established methodology and models, for consistency with the proposed manufacturing methodology ${ }^{18}$ as it continues to be developed and to include, when these become available, the actual fuel specifications (e.g., uranium isotopic content, impurities levels). These changes, to be implemented during FY 2010, will include modeling a zirconium interlayer between the U-10Mo foil and the aluminum clad. The impact of these fuel design changes on the core performance will be assessed. Sensitivity studies will be performed to support the development of fuel specifications.

A 3-D Monte Carlo-based depletion model with ALEPH has been developed for performing burnup simulations of the HFIR LEU core and for serving as an engine in the search of an optimal fuel design. This model is documented in the current report. Taking advantage of the latest developments in computational methods and tools, the established LEU core depletion model will be implemented into other 3-D Monte Carlo-based depletion tools to facilitate cross-checking and uncertainty estimation, with the goal of providing better estimates of the performance parameters and consequently minimize the uncertainties in safety margins. 



\section{REFERENCES}

1. R. D. Cheverton and T. M. Sims, HFIR Core Nuclear Design, ORNL-4621, Oak Ridge National Laboratory (1971).

2. R. T. Primm III, R. J Ellis, J. C. Gehin, D. L. Moses, J. L. Binder, and N. Xoubi, "Assumptions and criteria for performing a feasibility study of the conversion of the High Flux Isotope Reactor core to use low-enriched uranium fuel," CD Proceedings, PHYSOR 2006, Vancouver, Canada (2006).

3. R. T. Primm III, R. J Ellis, J. C. Gehin, D. L. Moses, J. L. Binder, and N. Xoubi, Assumptions and Criteria for Performing a Feasibility Study of the Conversion of the High Flux Isotope Reactor Core to Use Low-Enriched Uranium Fuel, ORNL/TM-2005/269, Oak Ridge National Laboratory (2006).

4. HFIR Technical Safety Requirements, ORNL/TM-12841, Rev. 9, Oak Ridge National Laboratory, (2005).

5. X-5 Monte Carlo Team, MCNP-A General Monte Carlo N-Particle Transport Code, Version 5, LA-CP-03-0245, Los Alamos National Laboratory (2003).

6. D. R Vondy, T. B. Fowler, G. W. Cunningham III, The BOLD VENTURE Computation System for Nuclear Reactor Core Analysis, Version III, ORNL-5711, Oak Ridge National Laboratory (1981).

7. SCALE: A Modular Code System for Performing Standardized Computer Analyses for Licensing Evaluation, ORNL/TM-2005/39, Version 6, Vols. I-III, January 2009. (Available from Radiation Safety Information Computational Center at Oak Ridge National Laboratory as CCC-750).

8. W. Haeck, An Optimum Approach to Monte Carlo Burnup, Ph.D. thesis, Ghent University, Belgium (2007).

9. N. Xoubi and R. T. Primm, III, Modeling of the High Flux Isotope Reactor Cycle 400, ORNL/TM2004-251 (2005).

10. RSICC Computer Code Collection CCC-371, ORIGEN 2.2. Available from RSICC, Oak Ridge National Laboratory (2002).

11. G. Ilas, J. C. Gehin, and R. T. Primm, III, "New cross section processing methodology for HFIR core analysis,” CD Proceedings, PHYSOR 2008, Interlaken, Switzerland (2008).

12. M. D. DeHart, “An advanced deterministic method for spent-fuel criticality safety analysis,” ANS Transactions 78, 170-172 (1998).

13. N. Xoubi and R.T. Primm III, Investigation of Beryllium Internal Reflector Installation on the Fuel Cycle Length of the High Flux Isotope Reactor, ORNL/TM-2004/252, Oak Ridge National Laboratory (2005).

14. T.H. Newton, Jr., Development of a Low Enrichment Uranium Core for the MIT Reactor, Ph.D. thesis, Massachusetts Institute of Technology (2006).

15. H. A. Mclain, HFIR Fuel Element Steady State Heat Transfer Analysis, Revised Version, ORNL/TM-1904, Oak Ridge National Laboratory, 1967, as appended by T. E. Cole, L. F. Parsly, and W. E. Thomas, Revisions to the HFIR Steady State Heat Transfer Analysis Code, ORNL/CF-85/68 (1986).

16. R. T. Primm III, G. Ilas, and C. Galvez Velit, "Status of design effort for LEU fuel for the High Flux Isotope Reactor,” RERTR-2008 International Meeting on Reduced Enrichment for Research and Test Reactors, Washington, D.C. (2008).

17. ORNL/HFIR/USAR/2344, HFIR Updated Safety Analysis Report, Rev. 6.

18. G.A. Moore, et al., "Monolithic fuel fabrication process development at the Idaho National Laboratory,” RERTR-2008 International Meeting on Reduced Enrichment for Research and Test Reactors, Washington, D.C. (2008). 


\section{APPENDIX A. MATERIAL COMPOSITION FOR LEU FUEL}

The LEU fuel material considered, as mentioned previously in this report, is a metallic alloy containing $90 \mathrm{wt} \%$ uranium and $10 \mathrm{wt} \%$ molybdenum. The density of the fuel is $17.02 \mathrm{~g} / \mathrm{cm}^{3}$ and the enrichment is $19.75 \mathrm{wt} \%{ }^{235} \mathrm{U}$. The uranium initial isotopic composition used in the model is shown in Table A.1. As in the HEU fuel plate design, a filler material is used between the fuel meat and the clad; boron in the form of $\mathrm{B}_{4} \mathrm{C}$ is included in the filler for the IFE. The clad and the filler material compositions are shown in Table A1.

No detailed specifications are available at this time for the actual composition of the LEU fuel material (isotopic content, impurities), as mentioned before. When these specifications become available, the model will be updated accordingly.

Table A.1 Material composition for LEU fuel

\begin{tabular}{|c|c|c|c|}
\hline Material & $\begin{array}{c}\text { Density } \\
\left(\mathrm{g} / \mathrm{cm}^{3}\right)\end{array}$ & $\begin{array}{c}\text { Component } \\
\text { (element or nuclide) }\end{array}$ & $\begin{array}{c}\text { Content } \\
(\mathrm{wt} \%)\end{array}$ \\
\hline & & ${ }^{234} \mathrm{U}$ & 0.176 \\
& & ${ }^{235} \mathrm{U}$ & 17.775 \\
& & ${ }^{236} \mathrm{U}$ & 0.082 \\
& & ${ }^{238} \mathrm{U}$ & 71.967 \\
& & $\mathrm{Mo}$ & 10.000 \\
\hline & & $\mathrm{Al}$ & \\
& & $\mathrm{C}$ & 97.155 \\
Clad & \multirow{2}{*}{2.70} & $\mathrm{Si}$ & 1.000 \\
(AL-6061) & & $\mathrm{Cu}$ & 0.600 \\
& & $\mathrm{Fe}$ & 0.400 \\
& & $\mathrm{Cr}$ & 0.350 \\
& & $\mathrm{Mn}$ & 0.195 \\
& & $\mathrm{Ti}$ & 0.075 \\
& & $\mathrm{Ni}$ & 0.021 \\
& & $\mathrm{H}$ & 0.021 \\
\hline \multirow{5}{*}{ Filler } & \multirow{2}{*}{2.71} & $\mathrm{Al}$ & \\
& & $\mathrm{Fe}$ & 0.250 \\
& & $\mathrm{Si}$ & 0.250 \\
& & $\mathrm{Cu}$ & 0.175 \\
& & $\mathrm{Mn}$ & 0.025 \\
& & & \\
\hline
\end{tabular}





\section{ORNL/TM-2009/223/R1}

\section{INTERNAL DISTRIBUTION}

1. K. J. Beierschmitt (beierschmitt@ornl.gov)

2. S. M. Bowman (bowmansm@ornl.gov)

3. C. A. Blue (blueca@ornl.gov)

4. S. E. Burnette (burnettese@ornl.gov)

5. D. C. Christensen (christensend@ornl.gov)

6. R. A. Crone (cronera@ornl.gov)

7. R. J. Ellis (ellisrj@ornl.gov)

8. J. C. Gehin (gehinjc@ornl.gov)

9. G. Ilas (ilasg@ornl.gov)

10. J. H. Miller (millerjh2@ornl.gov)
11. L. J. Ott (ottlj@ornl.gov)

12. C. V. Parks (parkscv@ornl.gov)

13. R. T. Primm III (primmrtiii@ornl.gov)

14. R. R. Rawl (rawlrr@ornl.gov)

15. J. E. Rushton (rushtonje@ornl.gov)

16. L. J. Satkowiak (satkowiaklj@ornl.gov)

17. J. D. Sease (seasejd@ornl.gov)

18. K. A. Smith (smithka@ornl.gov)

19. S. J. Zinkle (zinklesj@ornl.gov)

20. ORNL Laboratory Records (hamrindr@ornl.gov)

\section{EXTERNAL DISTRIBUTION}

29. A. Adams, U.S. Nuclear Regulatory Commission, One White Flint North, 11555 Rockville Pike, Rockville, Maryland 20852-2738 (axa@nrc.gov)

31. R. A. Butler, Director, Research Reactor Center, 1513 Research Park Drive, Columbia, MO 65211 (ButlerRa@missouri.edu)

32. G. S. Chang, Idaho National Laboratory, P.O. Box 1625, Idaho Falls, ID 83415-3885 (gray.chang@inl.gov)

33. D. Chong, NA-212, U.S. Department of Energy, 1000 Independence Avenue SW, Washington, DC 20585 (Daniel.Chong@nnse.doe.gov)

34. H. E. Clark, U.S. Department of Energy Oak Ridge Office, P.O. Box 2001, Oak Ridge, TN 37831 (hkc@ornl.gov)

35. D. Diamond, Brookhaven National Laboratory, P.O. Box 5000, Upton, NY 11973-5000 (diamond@bnl.gov)

37. H. D. Gougar, Manager, Fission \& Fusion Systems, INEEL, P.O. Box 1625, MS 3860, Idaho Falls, ID 83415-3860 (goughd@inl.gov)

40. D. Kutikkad, Assistant Reactor Manager-Physics, University of Missouri Research Reactor Facility, Columbia, MO 65211 (kutikkadk@missouri.edu)

41. J. Matos, Argonne National Laboratory, 9700 S. Cass Avenue, Argonne, IL 60439 (jim.matos@anl.gov)

42. C. McKibben, University of Missouri Research Reactor Facility, Columbia, MO 65211 (mckibben@missouri.edu)

43. D. M. Hewitt, Idaho National Laboratory, P.O. Box 1625, Idaho Falls, ID 83415-3750 (Dana.Hewitt@inl.gov)

44. T. Newton, MIT Nuclear Reactor Laboratory, 138 Albany St., Cambridge, MA 02139 (tnewton@mit.edu)

45. W. Richards, NIST Center for Neutron Research, 100 Bureau Drive, Stop 8561, Gaithersburg, MD 208998561 (wade.richards@nist.gov)

47. J. Roglans, Argonne National Laboratory, 9700 S. Cass Avenue, Argonne, IL 60439 (roglans@anl.gov)

48. J. Snelgrove, Argonne National Laboratory, 9700 S. Cass Avenue, Argonne, IL 60439 (jimsnelgrove@anl.gov)

49. P. Staples, NA-212, U.S. Department of Energy, 1000 Independence Avenue SW, Washington, DC 20585 (Parrish.Staples@nnsa.doe.gov)

50. Daniel M. Wachs, MFC 791 B-147, Idaho National Laboratory, P.O. Box 6188, Idaho Falls, ID 83415 (Daniel.Wachs@inl.gov)

51. R. E. Williams, NIST Center for Neutron Research, 100 Bureau Drive, Stop 8560, Gaithersburg, MD 20899-8560 (robert.williams@nist.gov) 